\title{
El grafismo: un arte entre escritura y dibujo
}

\section{Graphic art: an art between writing and drawing}

\author{
Jesús Espinosa Berdún ${ }^{1}$ \\ Prf. Dra.Roser Juanola Terradellas ${ }^{2}$
}




\section{Resumo}

El principal propósito del artículo es rebatir las malas concepciones sobre los inicios y la consolidación de la escritura, así como buscar prácticas de grafismo adecuadas que aporten beneficios que puedan acabar generando ideas emprendedoras. El enfoque del grafismo se abar$\mathrm{ca}$, tanto desde la escritura en la vertiente lingüística, como desde el dibujo en la vertiente artística. La intervención educativa, como parte empírica de la investigación, mediante metodologías activas e investigación acción, pretende aportar datos de todo el proceso de aprendizaje, tanto por lo que respecta a los aspectos de identificación y análisis, como a los de aplicación e interpretación, hasta los de creación. Este artículo es el resultado de una investigación cualitativa llevada a cabo en la escuela Pericot de Girona durante el periodo de prácticas del Grado de Maestro de Educación Primaria y dentro de la mención de educación artística. Ha contado con los alumnos de segundo de Primaria como muestra y un grupo de seguimiento compuesto por el docente especialista, la tutora de la investigación y el autor del proyecto.

Palavras-chave: Grafismo; lenguaje visual; educación emprendedora, digrafías, interrelación de las artes

\section{Abstract}

This article is the result of a qualitative research carried out in Pericot School in Girona during internship period of Grau de Mestre d'Educació Primària and in art education speciality. The study has had the children in second of primary as sample and a tracking group formed by the specialist teacher, the research mentor and project author. The main purpose of the article is to fight the problem of misconceptions about the beginnings and consolidation of writing and to find appropriate graphics activities that bring benefits that can end up producing entrepreneurial ideas. The graphics focus is analysed both from the writing in linguistic aspect and from artistic aspect. The educational intervention, as an empirical part of the research, aims to provide date of all learning process, both identification and analysis aspects, and implementation and interpretation, through to creation.

Keywords: graphics, visual language, entrepreneurship, plastic arts, primary education.

ISSN: 2175-2346

1 Universidad de Girona, Girona, Catalunia, Espanha espinosa 1993@hotmail.com

${ }^{2}$ Universidad de Girona, Girona, Catalunia, Espanha roser.juanola@udg.edu.es 


\section{Introducción}

\subsection{Arte, grafísmo y escritura}

Presentamos una reflexión sobre un tema que no es nuevo, pero sí lo es su enfoque. Las vinculaciones entre el arte y las distintas formas de escritura han existido siempre igual que, dentro de las libertades individuales, también se puede hablar de un estilo personal dentro del grafismo. Por lo contrario, la domesticación del grafismo conlleva la homogenización. Años atrás se conocía a la escuela que habían ido las personas por el tipo de letra que usaban, lo cual es lo mismo que decir que los alumnas habían tenido que renunciar a tener una letra personal, singular, que los identificara a cada uno de ellos y no como un colectivo concreto.

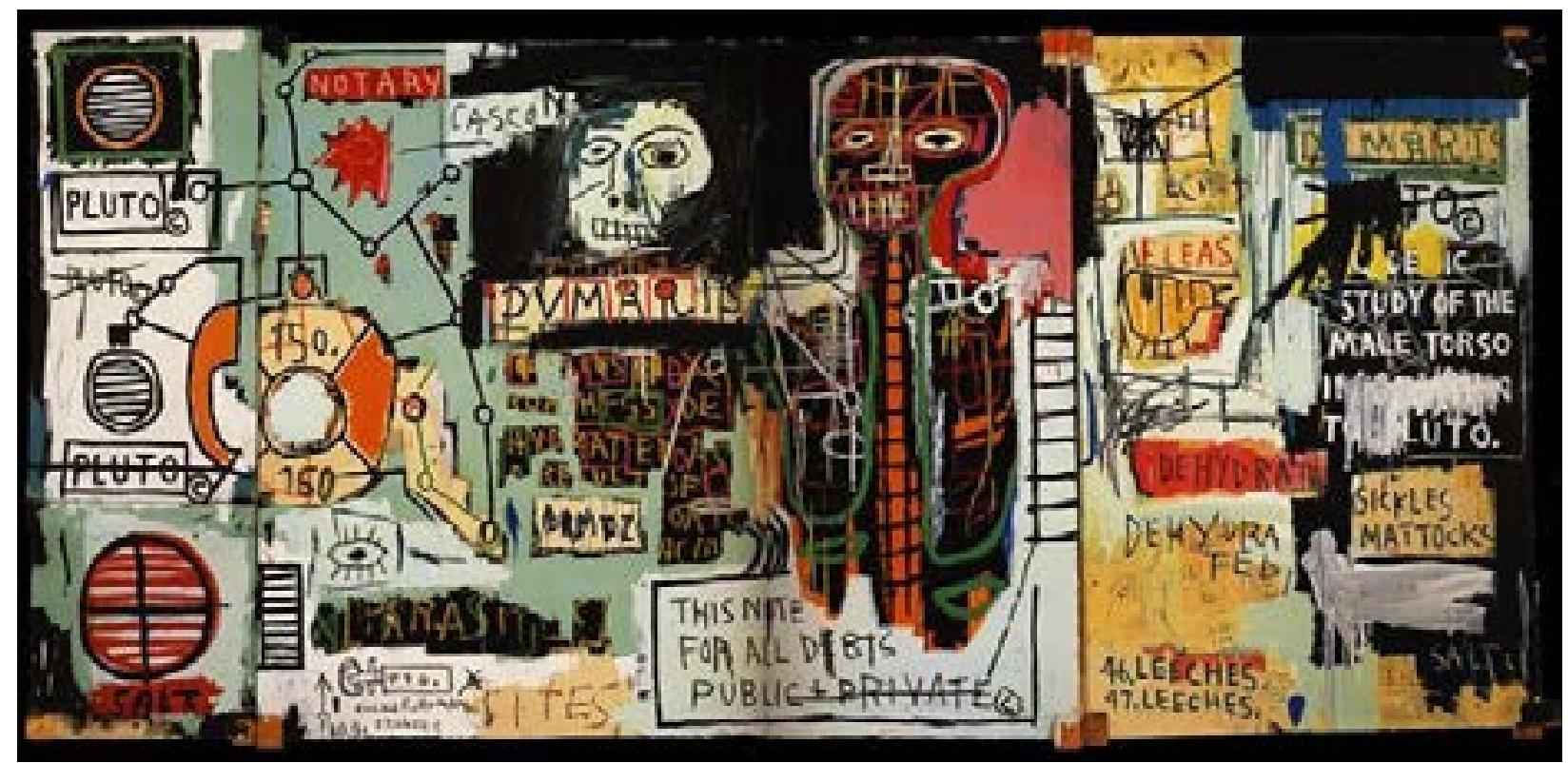

Fig.1- Jean-Michel Basquiat. Notary,1983

Las argumentaciones anteriores han ido creando un estado de conciencia en los docentes que ha dado como resultado una alienación del grafismo y una relegación de éste en pro de lo que se considera buena escritura. Lo cual demuestra que el concepto creado de una y otra, la escritura y el dibujo, no es del todo el adecuado. A menudo se da la paradoja que los niños que tienen mayor personalidad en su trazo y que además están dotados de gran expresividad, esta manera de destacar tan valorada des de la educación artística, se considera una torpeza en la evaluación de la escritura.

¿Cómo combatir esta situación? ¿Qué podemos proponer para desbloquearlo?

Pensamos que los planteamientos de la educación emprendedora que se están introduciendo actualmente en las escuelas pueden ser el andamio que facilite resolver por lo menos en parte esta situación. A partir de la coordinación de todo lo expuesto, detallamos a continuación, los pasos de la investigación. 


\section{ABCDEFGHIJKLM NOPQRSTUVXYZ abcdefghijklmnors tvxyz12345678}

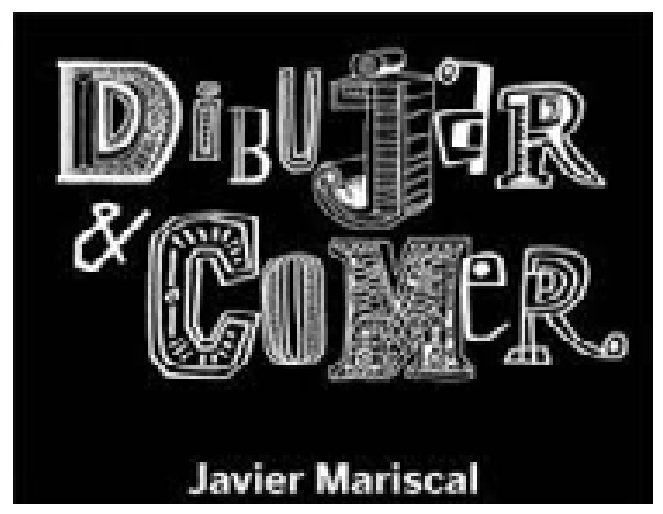

Fig.2 Alfabeto Gaudí de Ricard Giralt Miracle, 1962 Fig. 3 Obra gráfica de Javier Mariscal, 2013

\subsection{Objetivos de la Investigación}

Los objetivos principales de esta propuesta de investigación son:

. Conocer el proceso de evolución gráfica y a su vez detectar cuales son las variables que se implican en el desarrollo artístico de éste.

. Introducir las competencias emprendedoras en la educación primaria desde un enfoque que potencie la autonomía para el desarrollo del grafismo como arte y como escritura personal.

. Diseñar materiales didácticos sobre grafismo de utilidad para todas las artes visuales bajo directrices emprendedoras.

\subsection{Detectando la pregunta básica y argumentando sus fundamentos}

El problema de esta investigación está planteado a partir de las siguientes preguntas: ¿La observación atenta y con criterios evaluadores del proceso de evolución gráfica del alumnado a lo largo de la educación primaria (6-12 años) nos puede ayudar a detectar las carencias didácticas que presenta este proceso para potenciar también el desarrollo artístico? ¿Esta observación puede permitirnos, al mismo tiempo, centrar las variables que se implican en la mediación del aprendizaje por parte del docente?

Detectadas las principales variables que influyen en el grafismo en la Educación primaria y cuál es la visión general que se tiene en los centros educativos respecto a este elemento del proceso general del aprendizaje y del proceso artístico específico del mismo, sumado a la adquisición de la escritura y la práctica del dibujo, el objeto de estudio se enmarca dentro de una perspectiva de emprendimiento. Dentro de este marco y como aspecto fundamental hay que asumir el reto de superar los estereotipos gráficos, tanto por parte del alumnado como de los docentes, a fin de poner el énfasis en la creatividad y el trabajo cooperativo de los alumnos (marco emprendedor). 

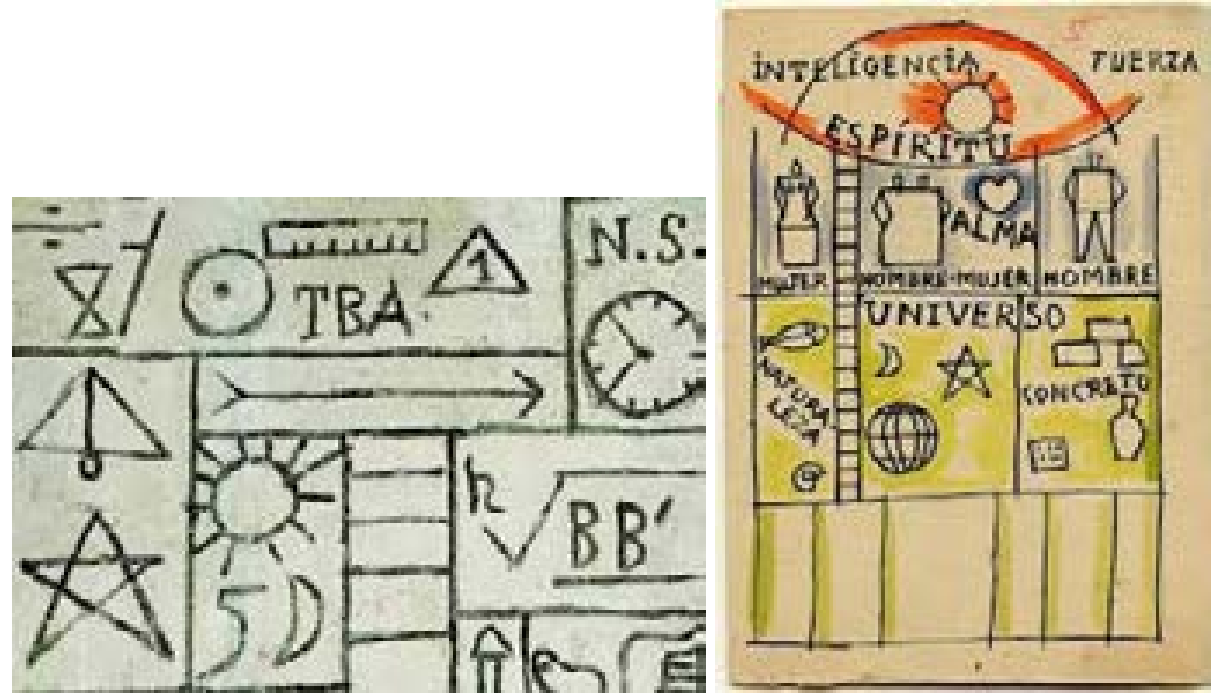

Figs.4-5 Joaquín Torres García, 1933

\subsection{Modelo de aprendizaje del centro educativo y contextualización de la propuesta}

Antes de dar paso a la fundamentación teórica de la investigación, es necesario presentar el modelo de aprendizaje por el cual se rige el centro educativo donde se llevó a cabo la investigación, así como el perfil de alumnado, sujeto de la parte de experimentación práctica. Según Coll et al. (1993) uno de los principales rasgos de este modelo se encuentra en el papel que ejerce el alumnado, el cual resulta ser activo y protagonista, ellos tienen el control sobre su aprendizaje y la respectiva construcción de nuevos conocimientos. Si bien esta concepción del individuo aprendiz no implica una pasividad por parte del docente, él es quien debe encargarse de relacionar los nuevos conocimientos con los conocimientos previos del alumnado.
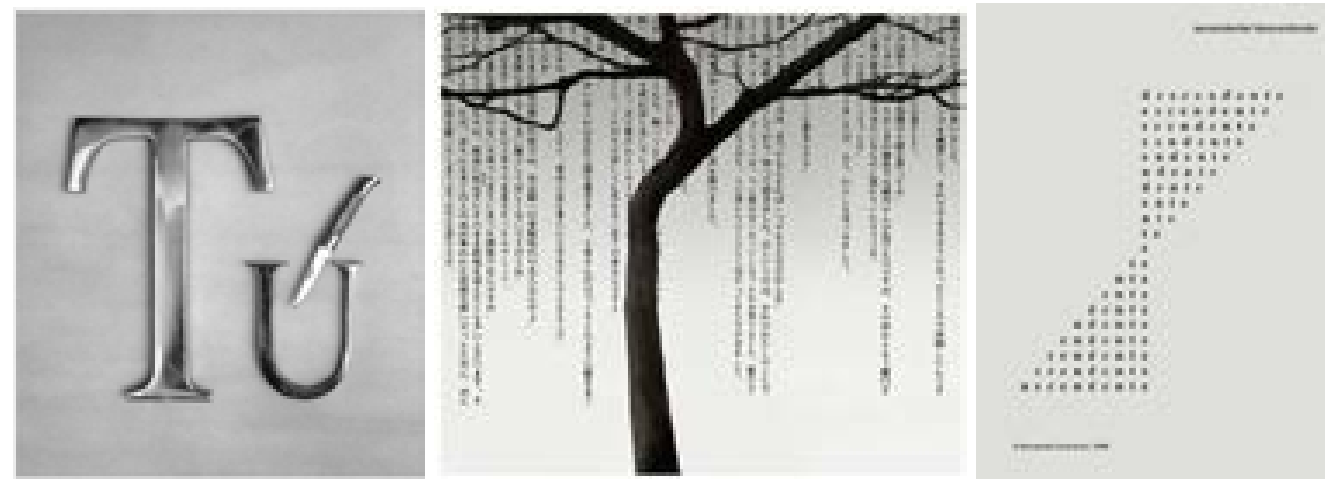

Fig.6-7 Chema Madoz, 2010-2011

Fig.8 Alexandre Guarnieri, 1998 


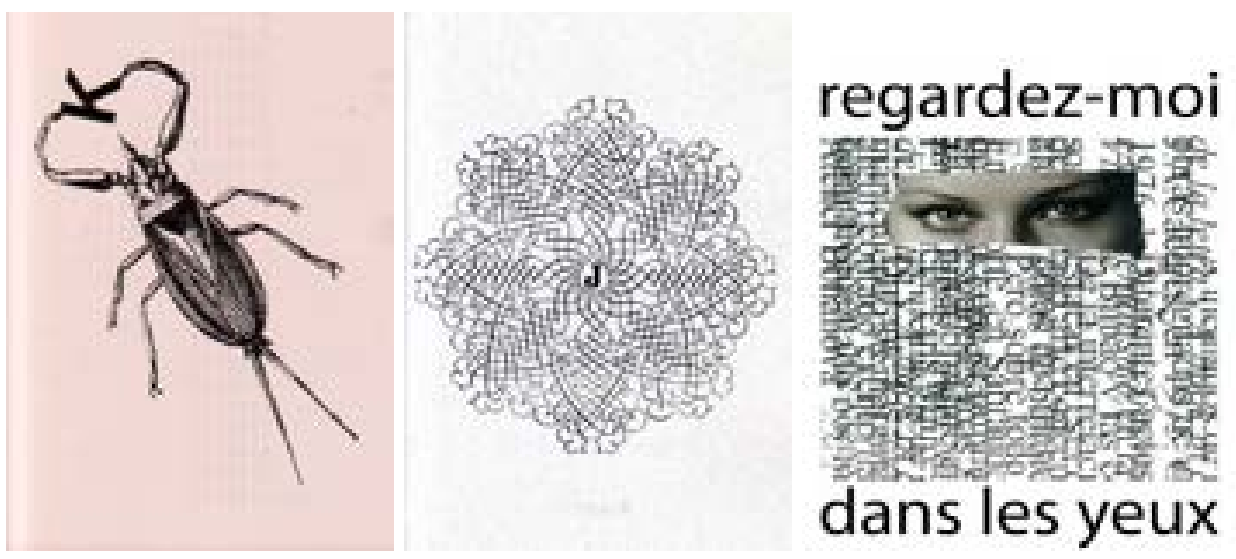

Figs. 9-10-11 J. M Calleja, Homenaje a Franz Kafka, 1984; Alfàbia, 2000; Indicacions verticals, 2011

Entrando ya en la descripción de la contextualización del alumnado, se trata de un grupo de alumnos de segundo de Primaria (7-8 años) con un nivel de asimilación de aprendizajes elevado. Teniendo en cuenta que en esta etapa educativa se encuentran finalizando el proceso de adquisición de la escritura alfabética (FERREIRO Y TEBEROSKY, 1979), cuando están iniciando la escritura ortográfica, que es el próximo paso que efectuaran, es muy interesante poner en marcha con ellos esta propuesta para fomentar la aceptación del propio estilo de letra, a la vez que abrir un abanico de experimentación en relación al grafismo por medio de actividades que no hayan llevado a cabo anteriormente con el especialista en artes plásticas.

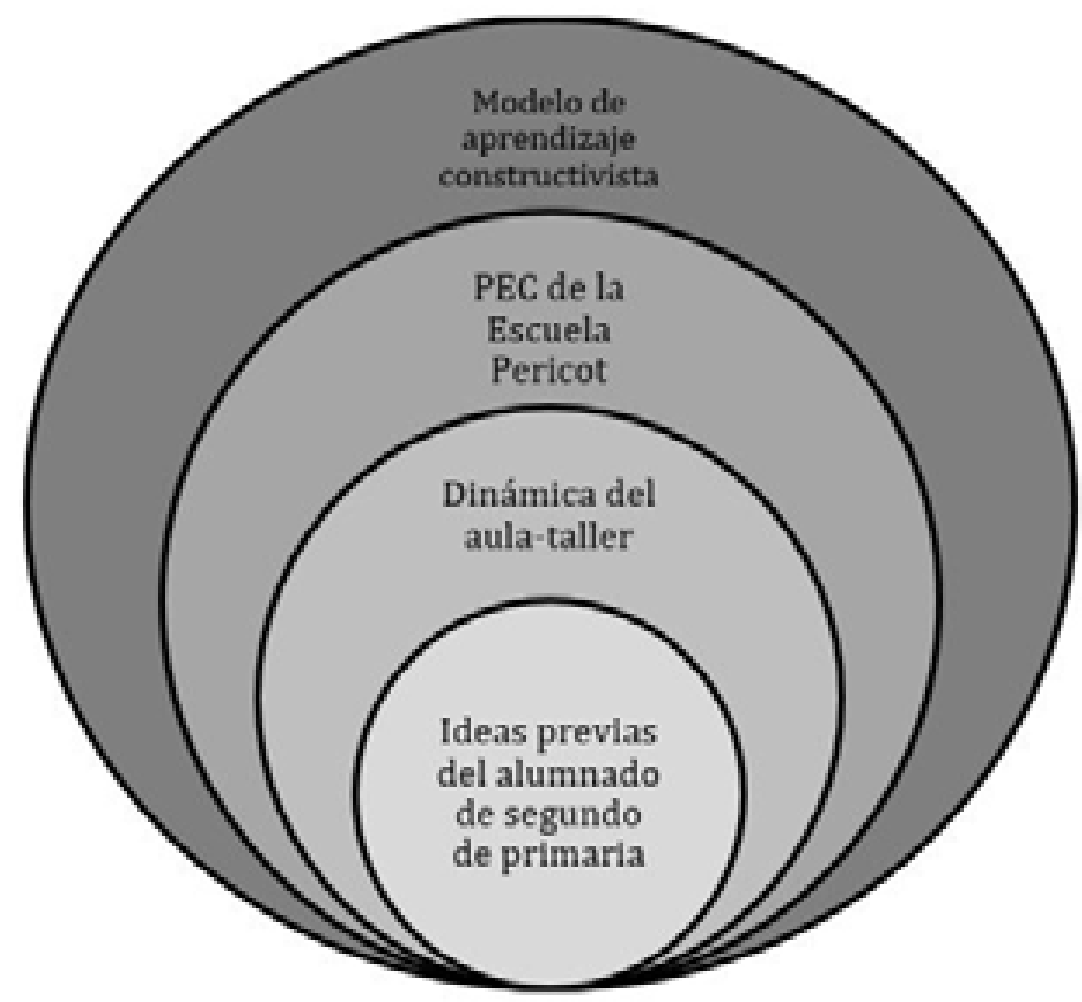

Fif.9. Fuente: Elaboración de los autores a partir del PEC de la Escuela Pericot (2013). 


\section{Fundamentación teórica}

\subsection{Qué se entiende por emprendimiento?}

El emprendimiento es la habilidad de ser flexibles y actuar con criterio propio ante los retos presentes y futuros. Es también la habilidad de generar ideas propias, convertirlas en proyectos factibles y saberlas llevar a cabo con les equipos adecuados. Este aspecto está convirtiéndose en vital en un mundo actual que se presenta en continua fluctuación, donde las reglas del juego se ven modificadas constantemente. Este concepto no engloba, como se cree des de algunos sectores, sólo el mundo empresarial, ya que no ha de buscar solo la riqueza económica, sino que puede perseguir también una mayor productividad artística e intelectual. Dentro de la actual vorágine transformadora, la familia y la escuela se convierten en pilares imprescindibles para que este espíritu emprendedor brote des de la infancia. Por lo tanto, los centros escolares tienen el deber de promover todas las capacidades que sirven para adquirirlo, con ayuda de la innovación, las nuevas metodologías y la transformación de las propuestas didácticas que restan obsoletas. De esta manera, los alumnos educados en este sentido, se forman en valores tan relevantes como la responsabilidad, el esfuerzo, la perseverancia, la motivación y el interés por los nuevos aprendizajes, la resolución de conflictos, la autonomía, la autoestima y la creatividad.

- A nuestro parecer, en el momento presente, el emprendimiento como iniciativa escolar, le queda mucho camino por hacer. Sin duda hace falta un cambio de paradigma que se oriente hacía un estilo de profesor más emprendedor, tanto en la manera de gestionar la acción conjunta de la clases como las iniciativas de los alumnos.

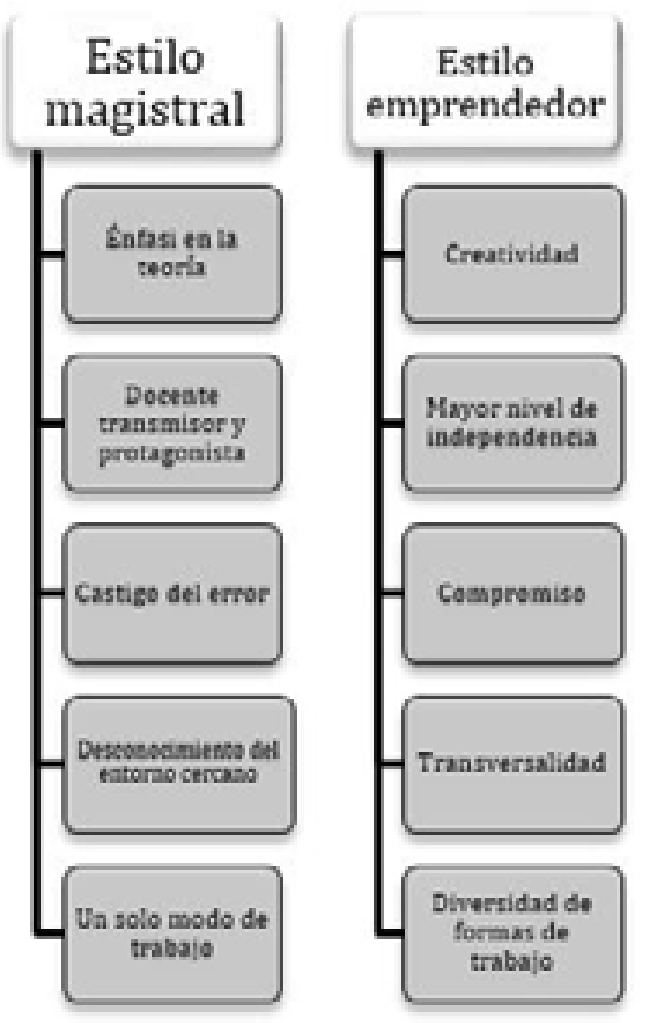

Fig. 10. Fuente: Elaboración de los autores a partir de Alemany et al. (2013). 


\subsection{Creatividad y compromiso, dos pilares fundamentales en los proyectos emprendedores}

El emprendimiento se concibe como la capacidad de abastecer y poner en marcha un proyecto o idea, nacido del potencial mental personal aun existiendo la posibilidad de correr riesgos, llevando a cabo una serie de cualidades tales como la confianza en uno mismo, el liderazgo y la resistencia ante el fracaso (ALEMANY et al., 2013). En esta línea, el individuo emprendedor lucha por lograr el objetivo aunque se interpongan en su camino obstáculos que en un momento dado puedan conducirlo erróneamente. Según Masgrau, Forasté y Cros (2012), es en este viaje donde la persona emprendedora ha de activar dos habilidades clave: la creatividad y el compromiso. Nos referimos a creatividad, citando a Jáuregui (2001), definida como "La capacidad de crear elementos nuevos y dinámicos o de resolver problemas, en contextos donde los recursos o instrumentos son escasos y/o limitados" (JÁUREGUI, 2001, p.8). El compromiso es la sensibilidad por detectar problemas o deficiencias de nuestro entorno (escuela, barrio o ciudad) y trabajar para mejorarlos o combatirlas.

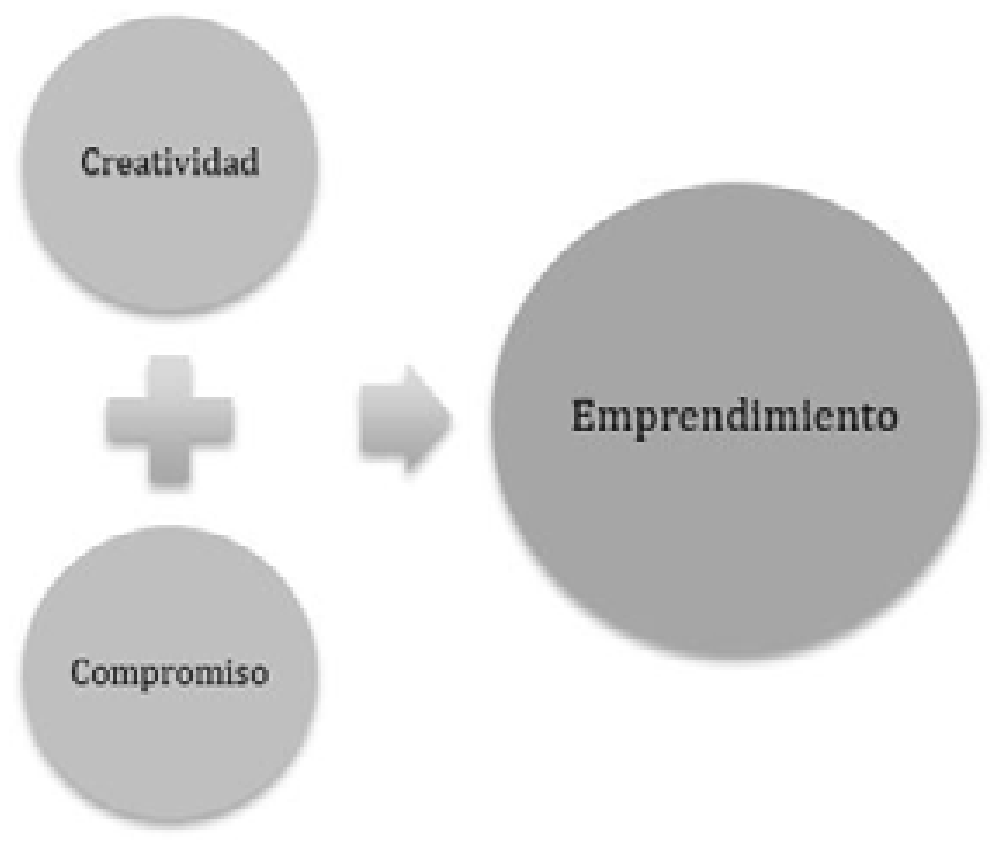

Fig.11. Fuente: Elaboración a partir de Masgrau, Forasté y Cros (2012).

Hasta el momento hemos podido comprobar cómo el emprendimiento permite poner en marcha proyectos innovadores, pero si bien el marco que lo engloba presenta la maquinaria necesaria para accionarla, precisamos un producto que moldear, al cual darle forma y que cumpla las características de este objetivo en un entorno concreto.

\subsection{El grafismo, la escritura y el dibujo: arte total}

La etimología de la palabra grafismo, proveniente del término griego graphein, incluye, según Costa (2013), el trazo y todas aquellas expresiones que surgen de éste. 
De esta forma el grafismo contiene dos subdivisiones: la primera incluye la escritura, la caligrafía y el arabesco y la segunda, el dibujo, el grabado y el esquema.

Las lecturas expertas sobre el tema que tratamos, demuestran que los dibujos y las pinturas son actos gráficos anteriores al nacimiento de la escritura y, des de oriente hasta occidente, tenemos abundantes ejemplos de ello. Actualmente dos formas de escritura predominan en el mundo: por un lado las escrituras con fundamento fonético donde cada signo representa un sonido de la lengua hablada y, por otro lado, en un grado mucho más inferior, las basadas en el principio ideográfico, donde los signos son representativos de la idea que se quiere transmitir. Sin embargo, este último tipo, también se ve complementado por signos fonéticos. Por ejemplo, pertenecen al primer caso las lenguas europeas y al segundo la lengua china.

¿Arte, escritura y dibujo? Los niños hasta los 3-4 años no aprenden a separar dos de las principales funciones del grafismo, por un lado la que guarda relación con la imagen y por el otro la que guarda relación con los signos. Según Lurçat (1980), la escritura nace en primera instancia como un trazo que completa el dibujo; y, no es hasta los 4-5 años, cuando se logra la reproducción independiente de las letras (se habrá pasado primero por los bucles y por los híbridos).

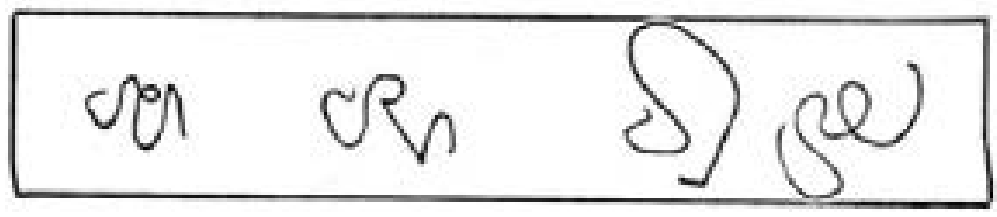

Fig-12.Fuente: Elaboración de Liliane Lurçat (1980).

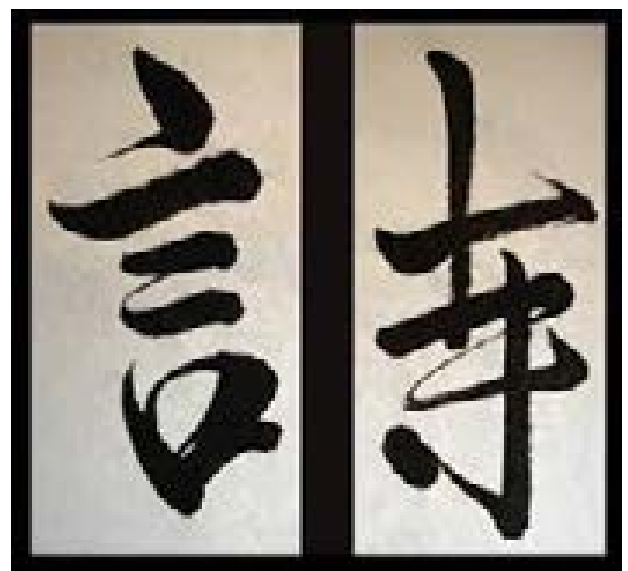

Fig-13.Escritura china.Fig-14 Alfabeto persa
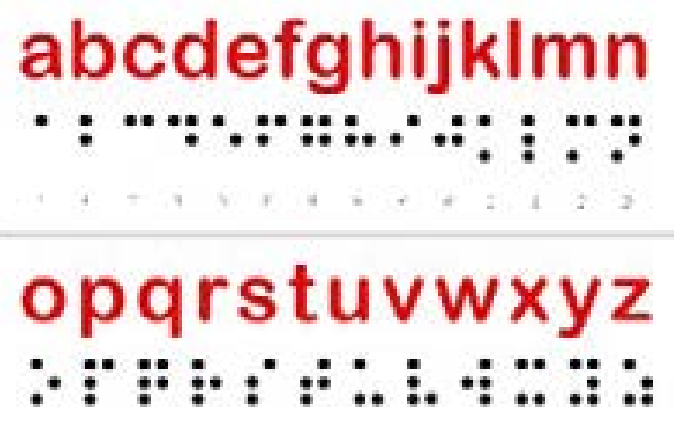

Fig.14 Alfabeto Braile 


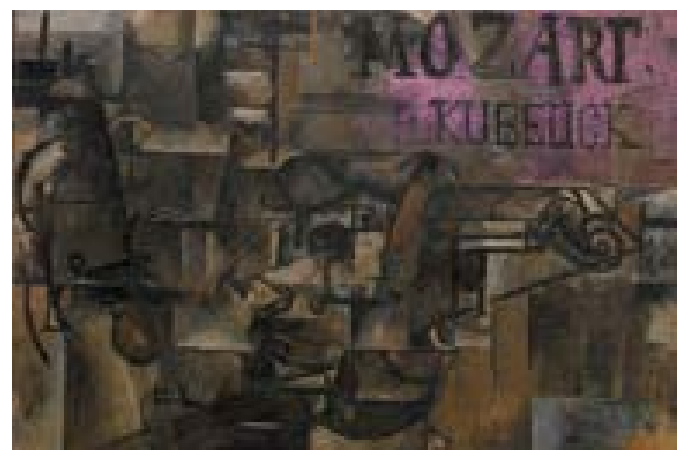

Fig. 15. George Braque Mozart Kubelick, 1912

A pesar de que el proyecto se focalice directamente sobre la etapa de educación primaria, el dibujo aparece en la vida del niño des del preciso instante en que es capaz de coger un útil y representar sobre un soporte cualquier tipo de trazo, fruto de las primeras descargas motrices. Por este motivo, nos remontamos entre el primer y tercer año de vida, donde en los dibujos de los niños y las niñas aparecen una serie de marcas, trazos y garabato.

\subsection{Variables que se implican en el grafismo}

Se ha creído conveniente escoger tres de entre todas las existentes dada su relevancia, sus posibilidades de aplicación, así como la etapa evolutiva de los alumno que constituirán la muestra. Las variables son las siguientes:

\section{a) Anomalías i disgrafías}

En un mundo diverso, podemos encontrarnos dentro de una aula con cientos de realidades diferentes, tanto a nivel cultural, cognitivo, madurativa, como de otros tipos. Si enfocamos entonces nuestra mirada en el ámbito de la escritura, existirá la posibilidad de detectar algunas variables que sobresalgan de los estándares de la adquisición de esta habilidad; una de ellas es la disgrafía.
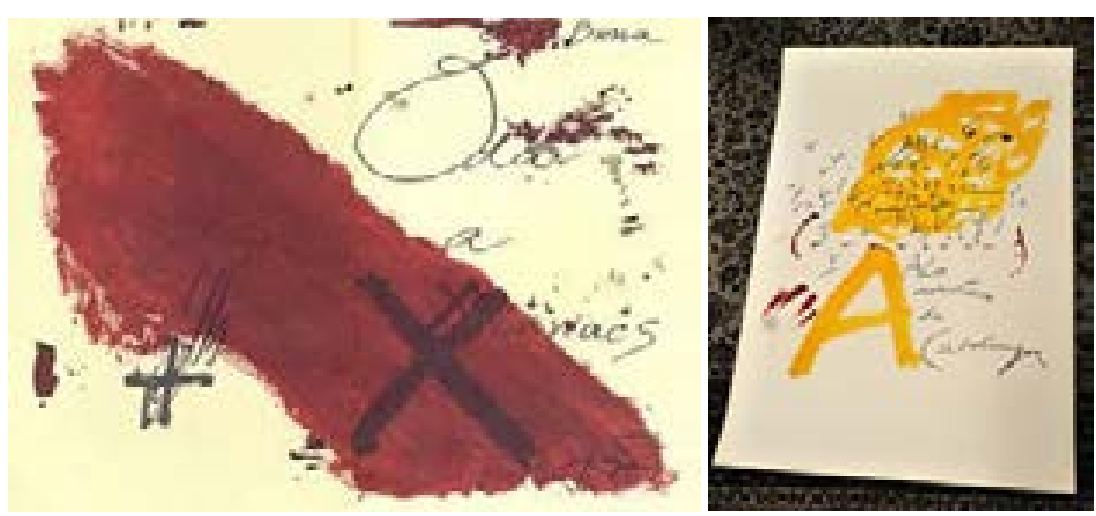

Fig-16-17. Antoni Tàpies 


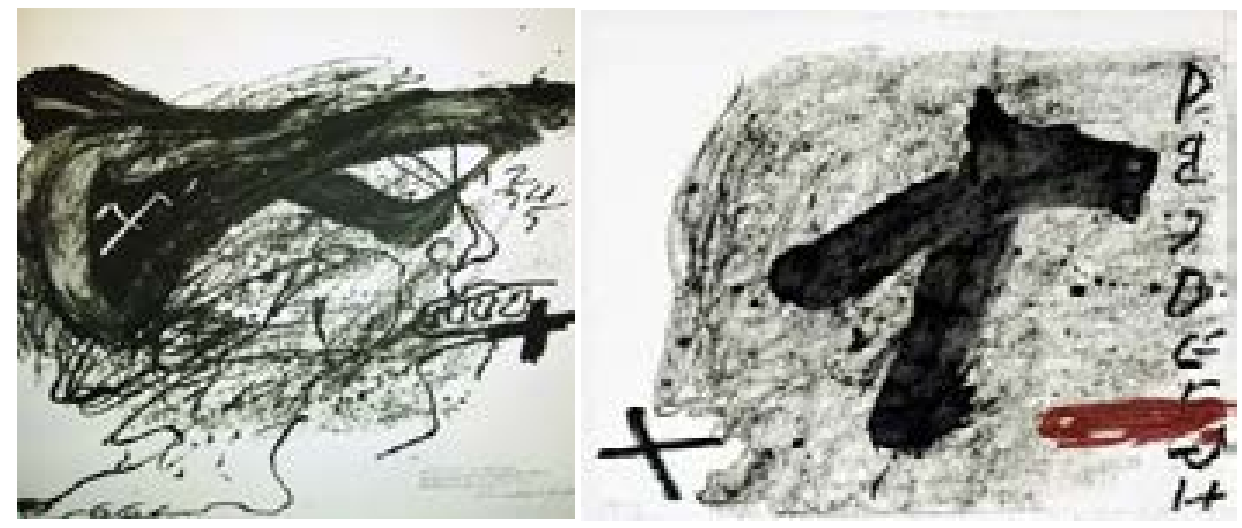

Fig.18-19. Antoni Tàpie

Entonces, hablamos de disfrafía cuando nos referimos a un trastorno de la escritura que puede afectar tanto a la forma como al contenido de esta. ¿Pero cómo podemos percibirla? Pues, cuando la cantidad de la escritura de un niño y su velocidad gráfica son deficientes, para su edad cronológica, aun cuando no sufre ningún déficit neurológico o intelectual (Rigal, 2006). Acto seguido, se exponen algunos de los rasgos más característicos de este trastorno:

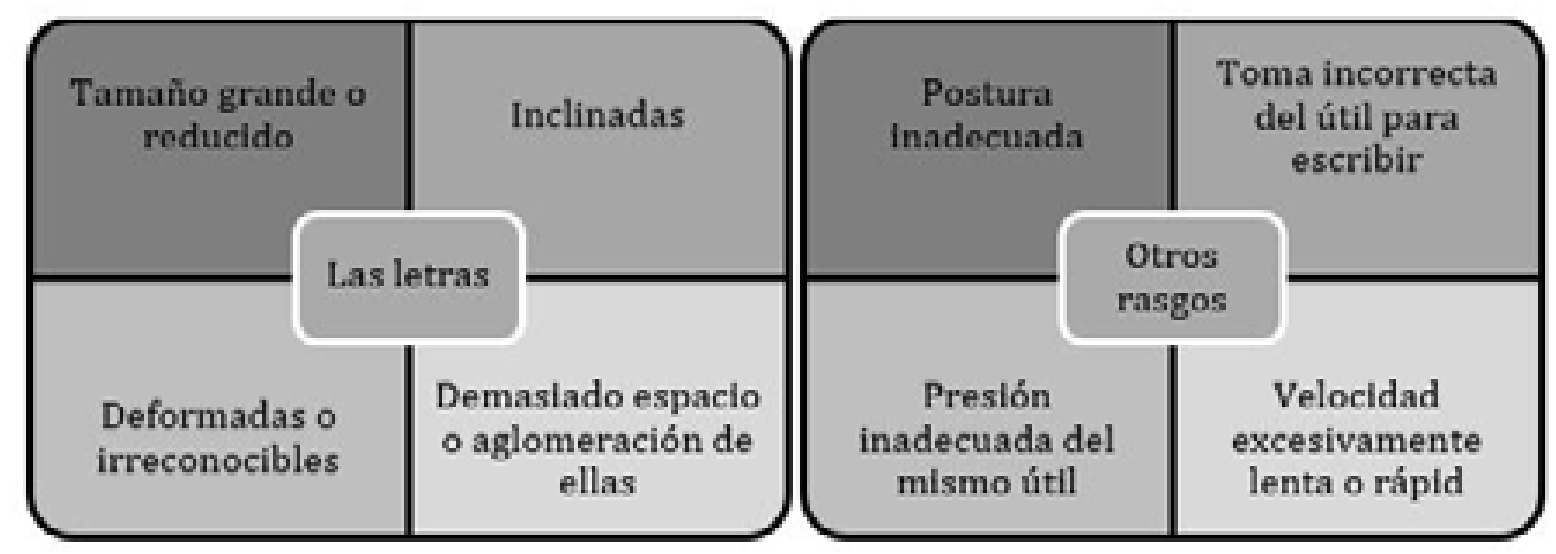

Fig-20 Fuente: Elaboración de los autores a partir de Rigal (2006).

Nuestro estudio pretende plantear que muchos diagnósticos sobre la escriptura son relativos y podria decirse que también muy sesgado. Son visiones que aportan un único punto de vista, de tal manera que la belleza de los signos gráficos que han conseguido algunos artistes relevantes como puede ser Antoni Tàpies, des de óptica anteriorment expuesta, podrían ser catalogados como disgráficos. Es esta paradoja la que nos interesa presentar.

\section{b) Formato y distribución del espacio}

Cualquier actividad gráfica precisa ineludiblemente de un formato y de una correcta distribución del espacio. Se entiende como formato la estructura del soporte y las dimensiones sobre las cuales se ejecuta el acto gráfico. El soporte más utilizado en las aulas continúa siendo el papel (diversas variedades), si bien, actualmente, también ha aterrizado con fuerza el soporte digital. 
El modo más simple de distribuir nuestras representaciones gráficas en el espacio nos ha venido inculcado por dos direcciones básicas, la vertical y la horizontal. Teniendo en cuenta este aspecto, es habitual que la mayoría de actividades gráficas que se realizan sigan esta premisa. Por ejemplo, la escritura alfabética se realiza en horizontal, de igual manera que los dibujos se efectúan en soportes que basan su estructura en cuatro ángulos rectos, porque presentan forma de rectángulo o cuadrado (incluso en el diseño gráfico digital). Lo podemos observar en la obra de Jaume Plensa, autor que ha adecuado las letras a todos las posiciones, tamaños, direcciones y sentidos. La obra de los artistas, que se crea siempre a partir de la libertad, abre nuevas puertas expresivas en las que tanto el autor como el espectador, caminan por espacios creativos.

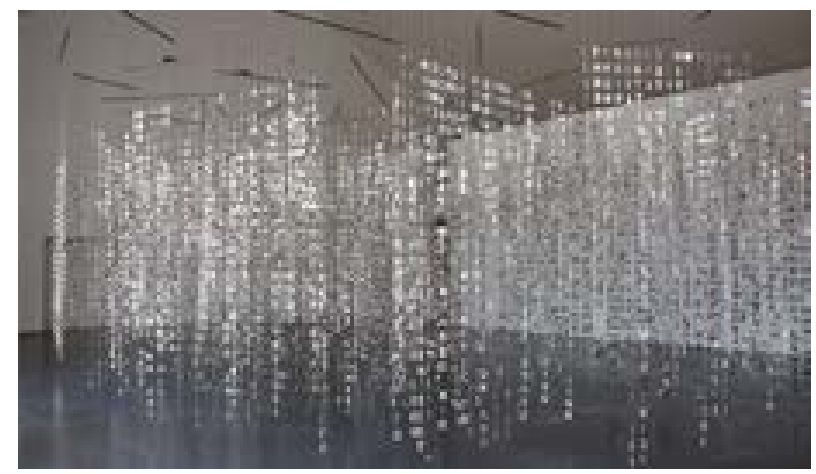

Fig-21.Jaume Plensa, 2015

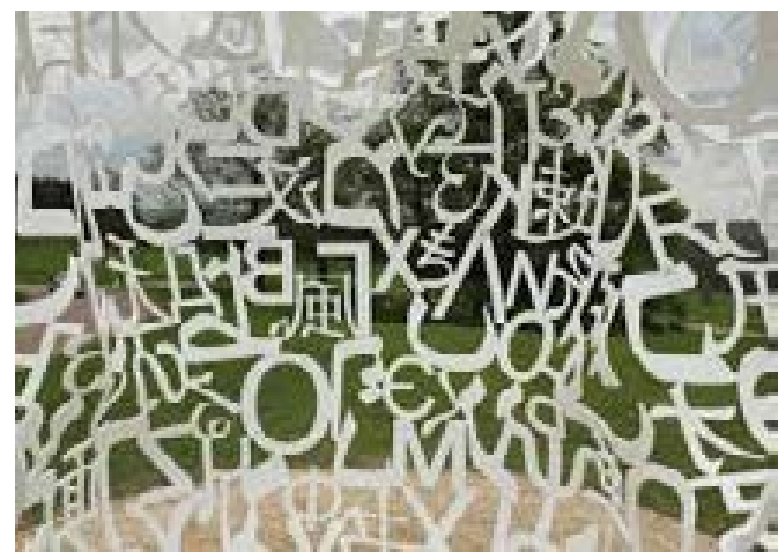

Fig.-22.Jaume Plensa. 2010

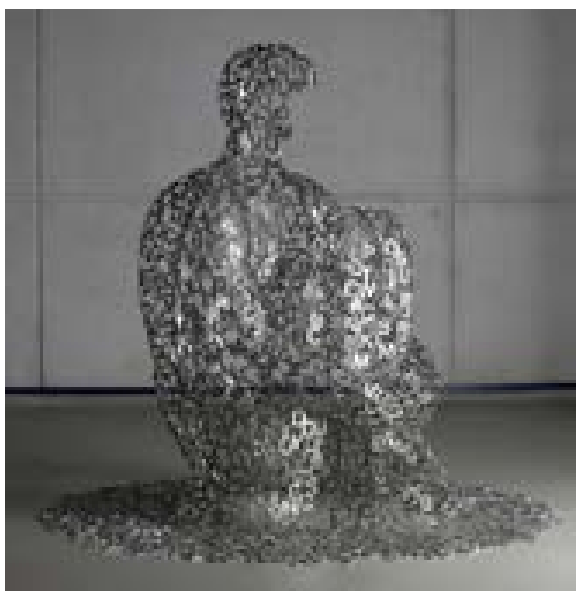

Fig.23-Jaume Plensa, 2010 


\section{c) Presión}

Cuando hablamos de presión nos referimos a la fuerza ejercida con un útil determinado sobre un soporte a la hora de realizar cualquier grafismo. Esta presión puede abastecer un amplio abanico de variaciones; así pues, la presión puede resultar firme, irregular, débil, fraccionada, temblorosa, fuerte, etc. (LÓPEZ et al., 2014). Algunas de estas posibilidades (temblor, demasiado irregular, etc.) ayudan a proyectar, juntamente con otros datos, ciertos trastornos de aprendizaje. Sin embargo, no siempre es así, siempre que se presente dentro de los parámetros de la "normalidad", sino que es una marca identificativa de nuestra personalidad, como lo son también el tamaño o la forma de las letras.
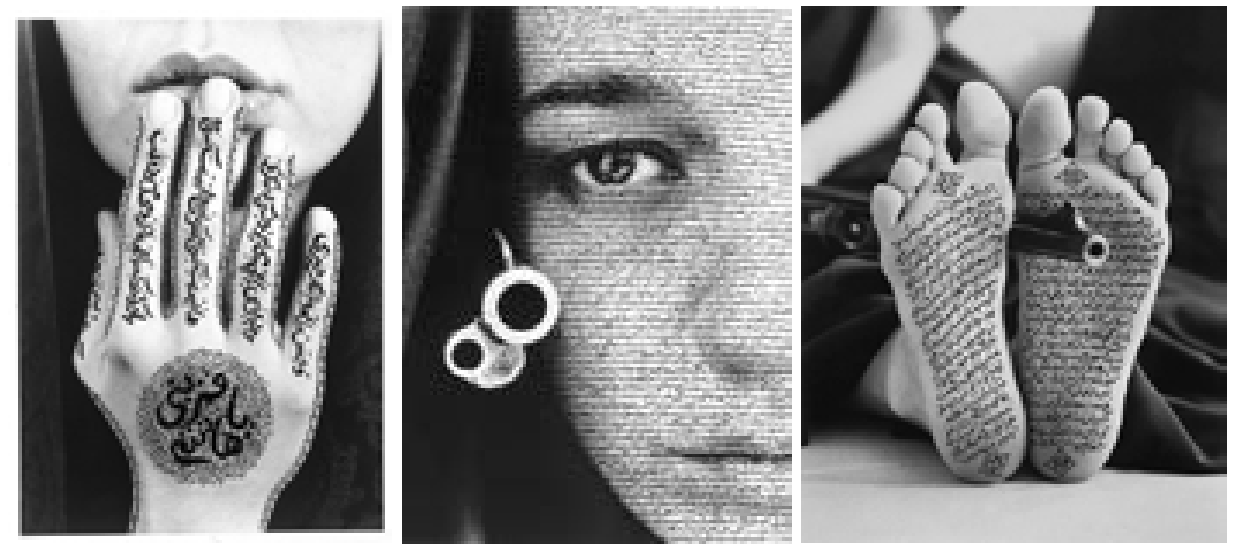

Fig.24-25.Sirin Nashat, 2013

Fig.26- Sirin Nashat 2013

Sin embargo en el campo artístico caben todos los recursos y la presión incluso puede ser algo efímero, momentánea, proyectado con recursos tecnológicos como algunas de las proyecciones corporales de Sirin Nashat, autora iraní que usa infinidad de estrategias siempre intentado ir más lejos y buscando provocar nuevas sensaciones.
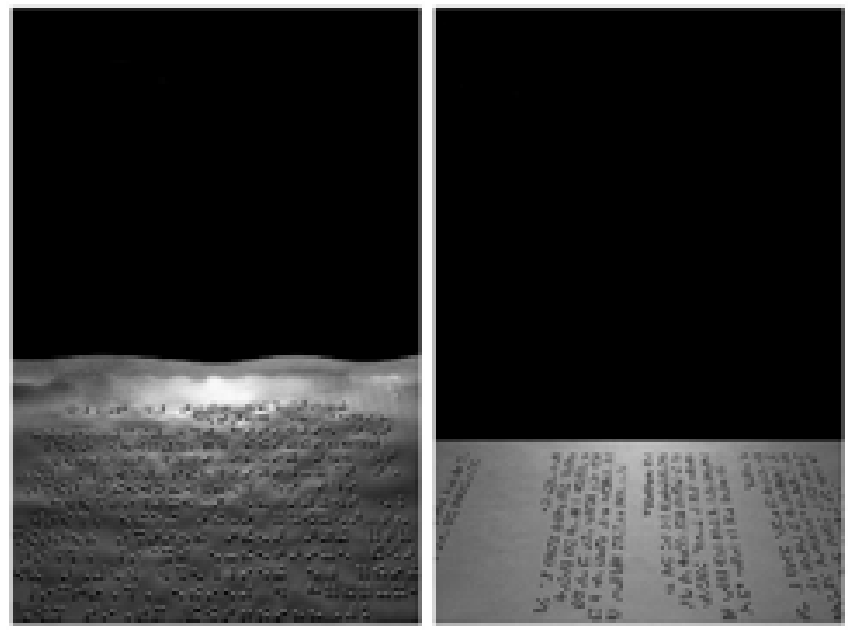

Fig.27-28. Joan Fontcuberta Serie Semióplis (1999-2001)

Joan Fontcuberta, fotógrafo e investigador de las artes visuales, nos acerca a otra mirada sobre los efectos visuales de la presión. En este caso tomando como motivo el alfabeto braille y provocando distintas lecturas estéticas sobre sus textos. A partir de variar la intensidad de la luz, la distancia y otros efectos, la presión que se 
ha ejercido en el plano, adquiere matices y sensibilidades impensables. Nos invita a valorar el braille como algo más que un recurso que aporta conocimiento a las personas que carecen de visión, sus fotos nos dan una mirada sensorial y estética.

\section{Metodología de la investigación}

Este proyecto educativo puede clasificarse atendiendo a diversos tipos de investigación. En primer lugar, lo podemos considerar una investigación cualitativa según Grajales (2000) puesto que los fenómenos sometidos a estudio son de un elevado grado de complejidad, requiriendo que se active un análisis subjetivo de las cualidades

Es necesario también exponer que la investigación que presentamos es transversal (Grajales, 2000), pues se trata de un estudio sobre el grafismo fundamentado en actividades llevadas a cabo en momentos concretos y en grupos de

niños de una misma edad, sin que este estudio presente una continuación en el tiempo.

\subsection{Planteamiento de la intervención educativa}

\subsubsection{Origen del proyecto}

La idea nace de una incentivación propia como consecuencia de mi relación directa con algunos miembros del grupo de investigación GREPAI, especialmente en referencia a el emprendimiento, tal y como se ha detallado en la fundamentación teórica.

\subsubsection{Sondeo de les ideas previas}

Han sido sondeadas algunos de los conocimientos previos del alumnado, así como algunas ideas y opiniones de cuatro docentes que interaccionan diariamente con la muestra escogida.

\subsubsection{Calendario y justificación de las sesiones}

Este proyecto consta de 9 actividades repartidas en 12 sesiones. Si bien, debería detallarse que antes de la primera actividad se ha llevado a cabo una encuesta individual para extraer información en relación a las grafías de los alumnos que pertenecen a la muestra. Las 9 sesiones acordadas se justifican en la intención de dar respuesta a tres fases estipuladas, a través de las cuales han de pasar los alumnos durante 6 semanas, si queremos lograr los objetivos marcados en el inicio del proyecto.

Así, en primera instancia, es necesaria una encuesta y una sesión de extracción de ideas previas en relación a las grafías, tanto de la propia como de la de compañeros. Después, las diversas sesiones programadas para la fase de expresión permiten experimentar con algunas de las variables implicadas en el grafismo y, por tanto, dada la importancia, se ha considerado oportuno que al menos haya dos sesiones por variable. Finalmente, la última parte relacionada con la fase de creación artística, donde se activa el contexto emprendedor, requiere también de más de una sesión. 


\subsection{Criterios de investigación evaluadores para recoger evidencias}

Los criterios se encuentran distribuidos en tres grupos clave que se presentan acto seguido en formato de pirámide:

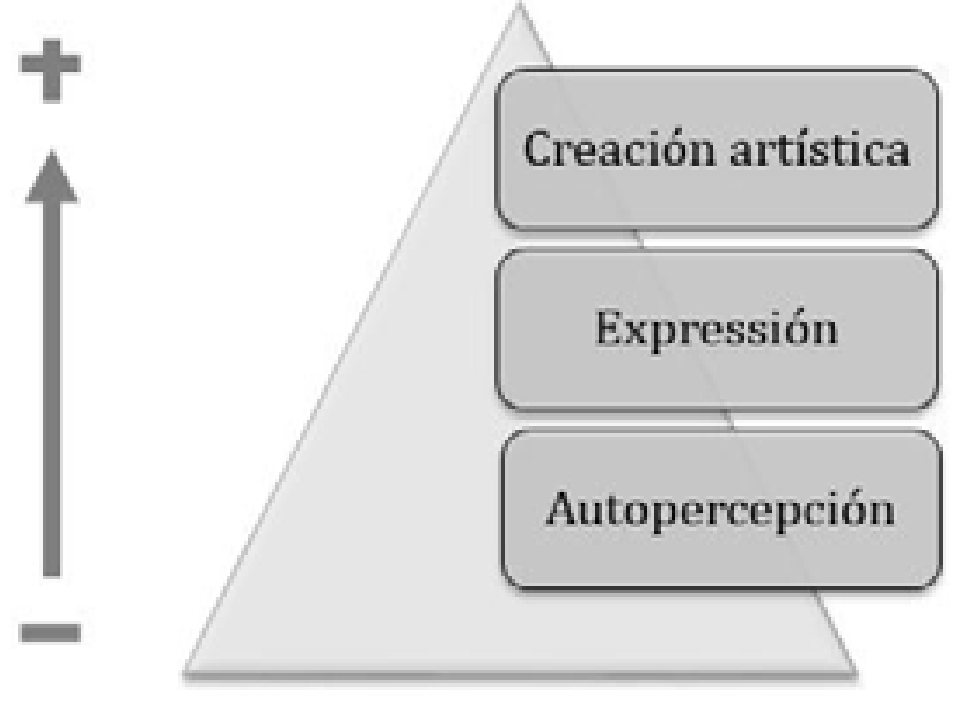

Fig- 29.Fuente: Elaboración de los autores

Con esta representación se pretende poner de manifiesto los tres escalones básicos por donde ascenderán los alumnos durante la experiencia práctica. Conviene destacar que el grado de intervención va de menor a mayor actividad. En primer lugar, nos encontramos con los criterios enmarcados dentro de la fase de autopercepción, donde se pretenderá que los alumnos experimenten un diálogo previo en relación a sus letras. Entonces, en este punto lo que se tendrá en cuenta principalmente serán habilidades de pensamiento inferior tales como identificar reconocer, interpretar, comparar y clasificar. Por lo tanto, en este caso, las actividades que se efectuaran serán de dificultad baja, para garantizar un proceso cognitivo coherente de su aprendizaje.

\begin{tabular}{|l|l|}
\hline \multicolumn{2}{|c|}{ AUTOPEREPCIÓN } \\
\hline \multicolumn{1}{|c|}{ Criterios } & \multicolumn{1}{c|}{ Justificación } \\
\hline $\begin{array}{l}\text { 1. Identificación i análisis gráfico previo } \\
\text { de los niños. }\end{array}$ & $\begin{array}{l}\text { Se busca llevar a cabo un pequeño va- } \\
\text { ciado para extraer una breve concepción } \\
\text { sobre cuál es la percepción que tienen } \\
\text { los niños sobre su propia letra. }\end{array}$ \\
\hline $\begin{array}{l}\text { 2. Comparación y clasificación de diver- } \\
\text { sos estilos de grafías. }\end{array}$ & $\begin{array}{l}\text { En este caso, la necesidad que busca la } \\
\text { aplicación de este criterio no es otra que } \\
\text { la de la percepción externa por parte de } \\
\text { los compañeros. De la crítica positiva } \\
\text { entre ellos, se puede extraer la verdade- } \\
\text { ra fuente negativa, las estigmatizaciones } \\
\text { que reciben de los adultos. }\end{array}$ \\
\hline
\end{tabular}

Fig- 29. Tabla 2. Criterios estipulados para la fase de autopercepción atendiendo a la clasificación de la Taxonomía de Bloom, renovada por Anderson y otros autores (2009). 
Más adelante, se avanzará a la fase de expresión, donde los criterios irán relacionados a una mayor implicación y participación por parte del alumnado y, por tanto, a habilidades de pensamientos de un nivel superior, como hacer, ejecutar y estructurar. Este será un puente intermedio que ayudará a gestionar el paso a la última fase. En ella, se podrán experimentar actividades y maneras de trabajar el grafismo, es el punto álgido de experimentación, donde se dará libertad, pero siempre bajo unos objetivos claros y coherentes. Así mismo, conviene comentar que es en esta fase donde se dará lugar a la práctica de las variables del grafismo.

\begin{tabular}{|l|l|}
\hline \multicolumn{2}{|c|}{ EXPESIÓN } \\
\hline \multicolumn{1}{|c|}{ Criterios } & \multicolumn{1}{|c|}{ Justificación } \\
\hline $\begin{array}{l}\text { 1. Aplicación de variables que afectan el } \\
\text { proceso del grafismo. }\end{array}$ & $\begin{array}{l}\text { Sequiere desplegar un abanico de inter- } \\
\text { venciones relacionadas a algunas varia- } \\
\text { bles que afectan al proceso del grafismo } \\
\text { de los niños, para así ver cómo las traba- } \\
\text { jan. }\end{array}$ \\
\hline $\begin{array}{l}\text { 2. Interpretación de las propuestas de } \\
\text { expresión sobre las variables que se im- } \\
\text { plican en el grafismo. }\end{array}$ & $\begin{array}{l}\text { Más allá de la ejecución, en esta fase } \\
\text { también es necesario ver como interpre- } \\
\text { tan cada una de las prácticas propuestas. }\end{array}$ \\
\hline
\end{tabular}

Fig-30.Tabla 3. Criterios estipulados para la fase de expresión atendiendo a la clasificación de la Taxonomía de Bloom, renovada por Anderson y otros autores (2009).

Finalmente, la cima de la pirámide de criterios, se encuentra enmarcada por la fase de creación artística, donde se requerirá que los alumnos activen las habilidades de pensamiento de nivel superior, especialmente diseñar, construir, colaborar, idear, elaborar y producir. La experimentación vivida previamente, permitirá llegar a este punto con menos miedo al fracaso; pues habrán cogido las riendas de todas las actividades y convertirse en pequeños emprendedores de un proyecto de confección de un material didáctico sobre grafismo.

\begin{tabular}{|l|l|}
\hline \multicolumn{2}{|c|}{ CREACIÓN ARTÍSTICA } \\
\hline \multicolumn{1}{|c|}{ Criterios } & \multicolumn{1}{c|}{ Justificación } \\
\hline $\begin{array}{l}\text { 1. Elaboración de un material didáctico } \\
\text { sobre grafismo. }\end{array}$ & $\begin{array}{l}\text { Este criterio quiere recoger la adquisici- } \\
\text { ón de aquello aprendido en las dos últi- } \\
\text { mas fases, con el añadido que sean los } \\
\text { alumnos quienes se encarguen de la ela- } \\
\text { boración de este material (bajo un con- } \\
\text { texto emprendedor). }\end{array}$ \\
\hline $\begin{array}{l}\text { 2. Edición y diseño del acabado digital } \\
\text { del material didáctico. }\end{array}$ & $\begin{array}{l}\text { El último criterio aspira a lograr un es- } \\
\text { calón más, donde los alumnos hayan de } \\
\text { actuar como editores, con el fin de unir } \\
\text { el mundo informático y a mano. }\end{array}$ \\
\hline
\end{tabular}

Fig-31.Tabla 4. Criterios estipulados para la fase de creación artística atendiendo a la clasificación de la Taxonomía de Bloom, renovada por Anderson y otros autores (2009). 


\subsection{Muestra seleccionada para aplicar la investigación}

La muestra seleccionada para aplicar a la investigación es un grupo de 2 n de primaria de la Escuela Pericot. El motivo de la elección no es otro que el conocimiento profundo hacia esta clase, dado que ha sido el aula donde el autor del proyecto ha impartido los dos tercios como docente generalista en prácticas. Este periodo temporal le ha permitido conocer el grupo y profundizar en cada una de sus particularidades, hecho por el cual ha podido construir a su lado una base firme de confianza y feedback que le repercutirá positivamente en la intervención práctica.

Asimismo, los rasgos característicos de este grupo son los siguientes:

Número de niños: 14

Número de niñas: 10

Nivel escolar: $2 n$ de primaria (entre 7 y 8 años). Ciclo inicial.

Características: En primera instancia, conviene mencionar que se trata de un grupo que presenta una diversidad cultural elevada, pues aproximadamente el $80 \%$ de los alumnos de la clase provienen de una nacionalidad que no es la catalana. Por otro lado el grupo muestra unas amplias y positivas aptitudes por aprender.

\subsection{Características de la intervención educativa}

Las evidencias han sido recogidas con diferentes dispositivos (encuestas, fotografías, grabaciones, notas de campo, etc.) y realizadas en diversos contextos dentro y fuera del centro educativo. Igualmente las dinámicas de grupo y estrategias llevadas a cabo han dado lugar a diferentes tipos de modos de trabajo. Finalmente, con respecto a los recursos y materiales utilizados, estos han sido muchos tanto de soporte digital como analógico.

\section{Análisis de los resultados}

Una vez efectuadas las diversas sesiones que constituyen la intervención educativa del proyecto, se da paso al análisis de los resultados. En este punto de la investigación entonces, se debate con todo el grupo de investigación.

La triangulación ha sido el enfoque pactado entre todos los miembros de la investigación, tanto investigadores participantes como no participantes. El proceso de triangular, tal y como el propio nombre indica, implica analizar la investigación des de tres puntos de vista diferentes; pero, no solamente eso, sino que, dicho con palabras de un doctor en diseño curricular y evaluación educativa (ARANEDA, 2006): "La triangulación es una herramienta o procedimiento técnico que sirve para dar consistencia interna y credibilidad a la investigación" (ARANEDA, 2006, p.19).

Llegados a este punto, el triángulo que emerge de esta investigación se en- 
cuentra constituido por los siguientes vértices: primeramente, por los criterios de investigación extraídos de la Taxonomia de Bloom renovada por Anderson y otros autores (2009); en segundo lugar, por el marco teórico, conformado por tres ejes que sustentan la investigación y, en tercer y último lugar, por la opinión del grupo de investigación.

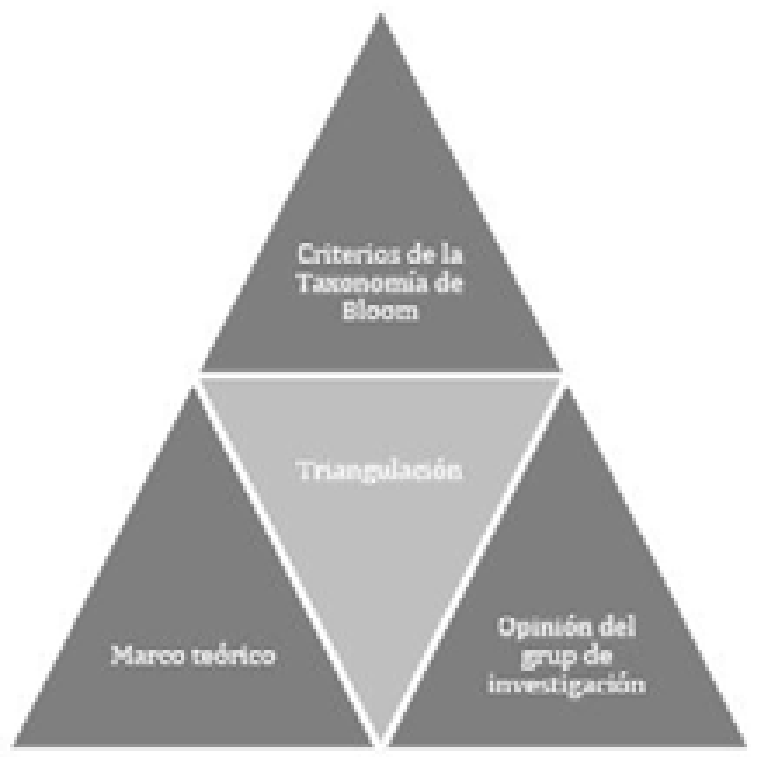

Fig-31.Fuente: Elaboración de los autores.

\subsection{Primer vértice: resultados a partir de los criterios de la Taxonomía de Bloom}

En este apartado se desea mostrar las evidencias obtenidas en las diversas fases de la intervención educativa del proyecto, avaluando los resultados a partir de los criterios de la Taxonomía de Bloom. Estos anteriores, distribuidos en las fases correspondientes del proyecto, son los siguientes:

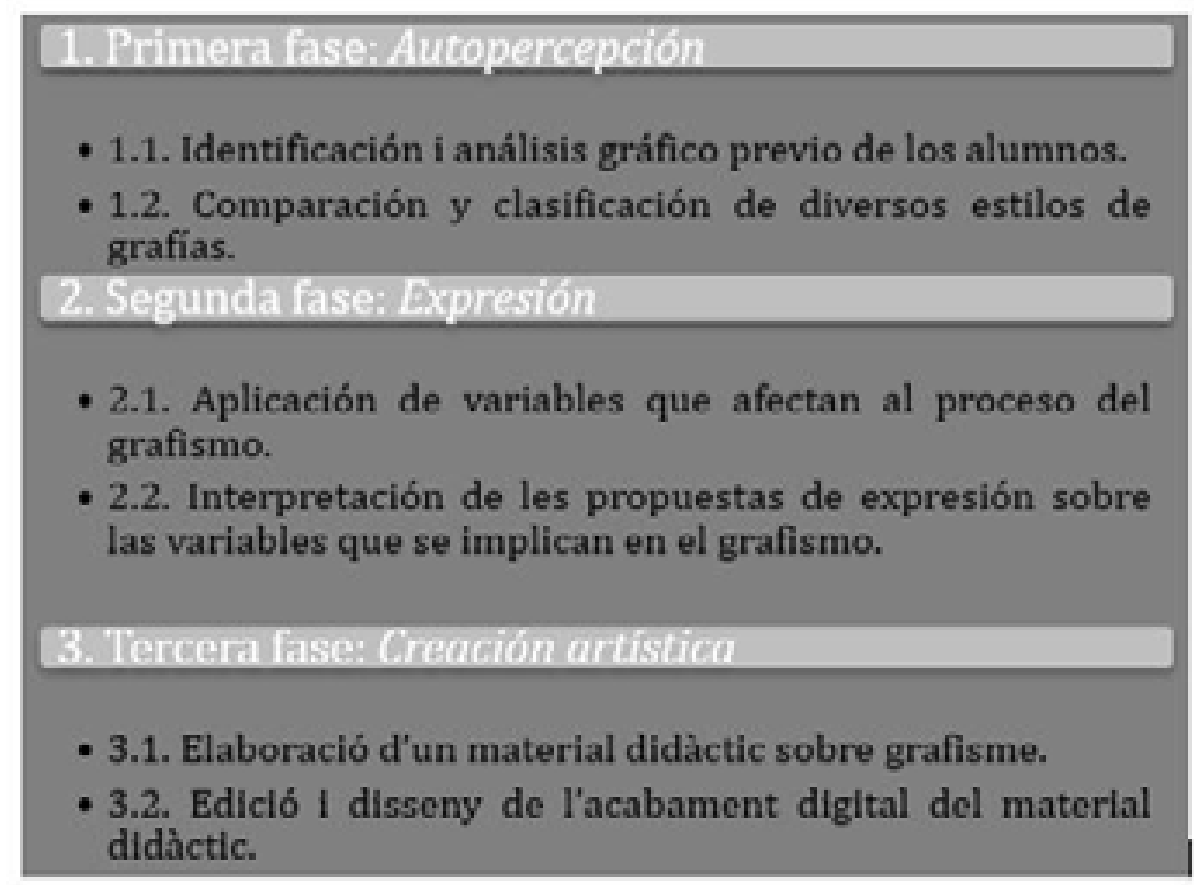

Fig.32. Tabla 5. Resumen de las fases de la intervención educativa 


\subsection{Resultados de la fase de autopercepción}

Las evidencias obtenidas son las encuestas los alumnos y los que intervienen sobre la muestra y la primera sesión de la unidad didáctica. Los resultados de esta fase serán evaluados a partir de los criterios de la investigación citados en los apartados, 1.1 y 1.2

\subsubsection{Vaciado de las encuestas realizadas a docentes del centro educativo}

Nube de palabras originado a partir del vaciado de las encuestas

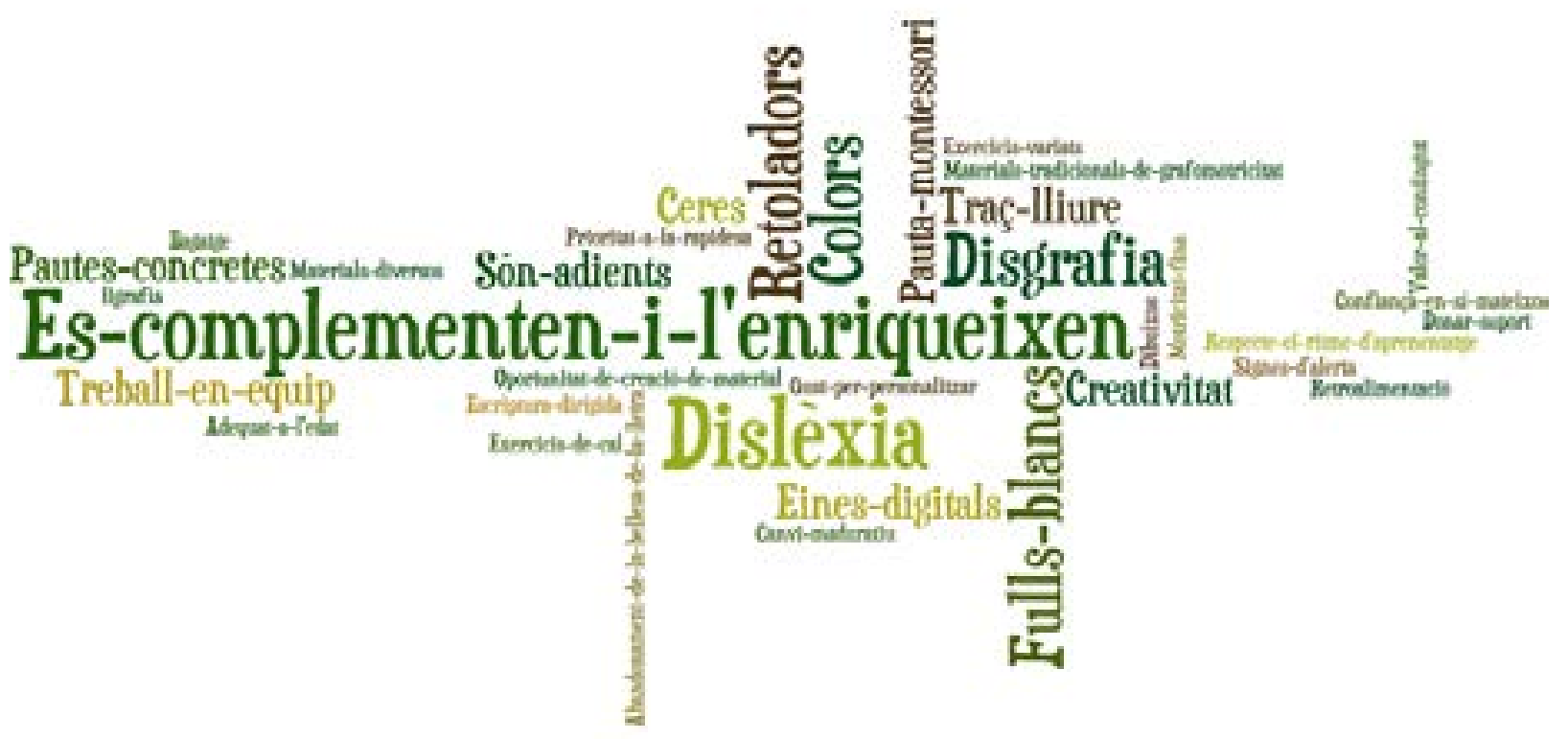

Fig-33.Fuente: Elaboración de los autores a partir de las encuestas docentes

Una vez efectuada la encuesta a cuatro docentes que se encuentran en contacto diario o semanal con la muestra del proyecto, se procede a la realización de un vaciado cualitativo sobre estas a partir de una nube de conceptos.

De las palabras más mencionadas por el profesorado encuestado extraemos los siguientes resultados:

1. Un buen entendimiento entre el grafismo y las nuevas tecnologías permite que estos se complementen y enriquezcan para fomentar un proceso cualitativo y diverso en la escritura.

2. Si bien las creaciones artísticas se desarrollan mediante todo tipo de útiles y soportes, no se han abandonado tres utensilios tradicionales como son los colores, rotuladores y ceras, dada la comodidad que supone el trabajo realizado con ellos.

3. Los docentes son bastante conscientes de la posibilidad de que existan alumnos con dificultades de aprendizaje a nivel de lectoescritura. Algunas de estas alteraciones que deben ser detectadas prematuramente son la dislexia y la disgrafía.

4. Finalmente, los maestros consideran relevante tres aspectos para la formación de personas emprendedoras: la creatividad, el trazo libre y el trabajo en equipo. 


\subsubsection{Vaciado de las encuestas efectuadas a los alumnos pertenecientes a} la muestra de la intervención educativa del proyecto

Nube de palabras originado a partir del vaciado de las encuestas.

\section{Molt-bonica}

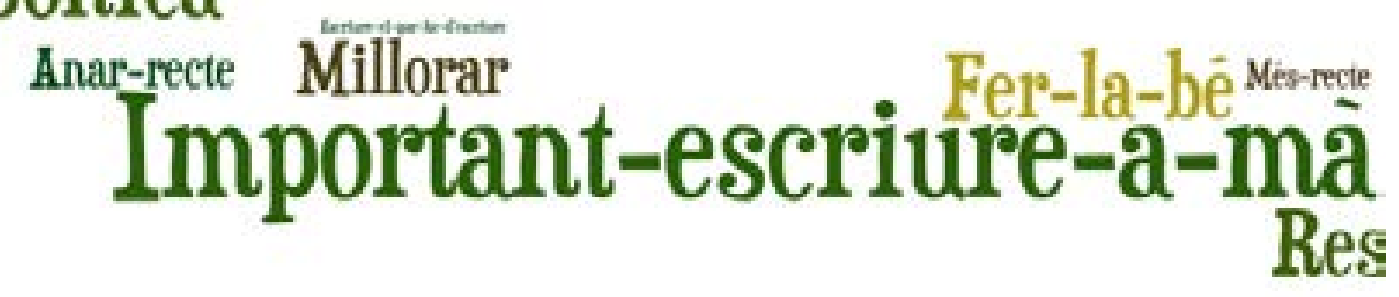

Fig-34.Fuente: Elaboración propia a partir de les encuestas.

Finalizada la encuesta a los alumnos que componen la muestra del proyecto, se procede a la elaboración de un vaciado cualitativo sobre esta. A partir de la nube de palabras se han extraído los siguientes resultados:

1. Los alumnos consideran relevante escribir a mano.

2. Las opiniones de los maestros con respecto a sus estilos de grafía suelen ser generalmente negativas, mientras que la de las familias positivas, aunque aparecen excepciones. Asimismo, un número considerable de alumnos no tienen constancia de las opiniones provenientes de sus compañeros de aula referentes a sus letras.

3. Una de sus mayores preocupaciones es la de intentar hacer bien la letra en el momento en que están ejecutando el acto psicomotriz. Por "hacer bien" entienden que la letra sea estéticamente correcta, tal y como les suele ser exigido por parte de los adultos.

4. De la elección de entre diferentes tipologías textuales, la más escogida fue la "Blackadder ITC", que se trata de un tipo de letra con cierta imprenta personal. Por tanto, puesto que los alumnos pertenecientes a la muestra se encuentran finalizando la etapa de ciclo inicial, podríamos recuperar las palabras del profesor especialista, Jordi Serra, quien asegura que: "los alumnos llegados a ciclo medio comienzan a mostrar el gusto por la personalización de la grafía"; entonces, es en este punto donde los alumnos experimentan con su propio trazo.

5. A casi la totalidad de los alumnos encuestados les gusta o se sienten satisfechos con su letra.

Acto seguido, con el vaciado de las encuestas efectuadas, llegan las evidencias de la primera actividad del proyecto, propuesta que pretendía ampliar el campo de la autopercepción, en este caso la externa. A continuación, se muestra un gráfico con los tres colores que los alumnos disponían para decidir a qué nivel les gustaba o no una letra que no fuese la suya, sino que la de un compañero o compañera de la misma edad.

A simple vista los resultados nos muestran que hay bastante equilibrio entre las tres opciones cromáticas que se pusieron al abasto de los niños para la realización de la prueba. La intención principal de la actividad era que se llevase a cabo una clasificación de las letras en función de un menor o mayor agrado (logro del criterio 1.2). 
Los alumnos a su vez que clasifican por colores, comparaban las diferentes grafías entre sí, activando habilidades de pensamiento de nivel inferior.

\subsection{Resultados de la fase de expresión}

\subsubsection{Resultados de la experimentación de las variables que inciden en el proceso del grafismo}

En este apartado se analizan las variables sometidas a estudio en la fase de experimentación del proyecto (bajo la evaluación de los criterios 2.1 y 2.2), con la intención de dar respuesta a una de las preguntas planteadas inicialmente y, así, conseguir dos de los principales objetivos de la investigación, poniendo especial énfasis en el segundo:

- Conocer el proceso de evolución gráfica y a la vez detectar cuáles son las variables que se implican en el desarrollo de éste.

- Someter a estudio algunas de las variables anteriores para profundizar en sus características en relación al grafismo.

Las variables escogidas $y$, su respectivo despliegue de rasgos que influyen en cada una de ellas, son las siguientes:
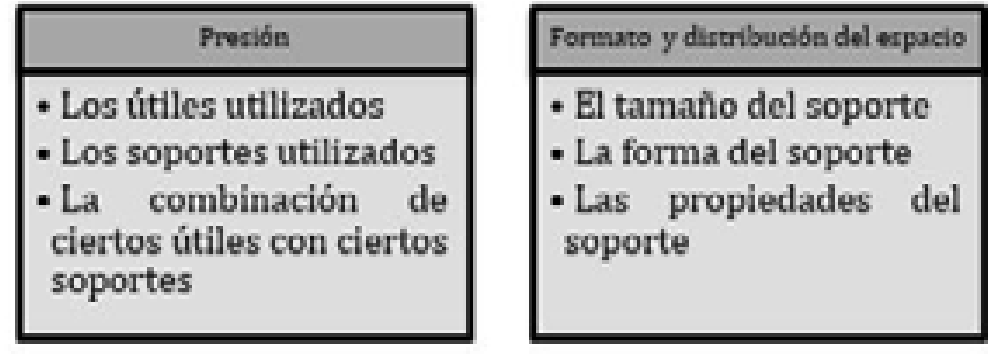

Fig-35..Fuente: Elaboración de los autores

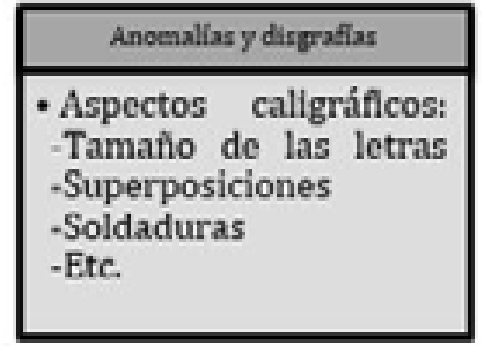

En cuanto a las actividades la experimentación estaba asegurada. A continuación se muestran algunas imágenes a modo de ejemplo.
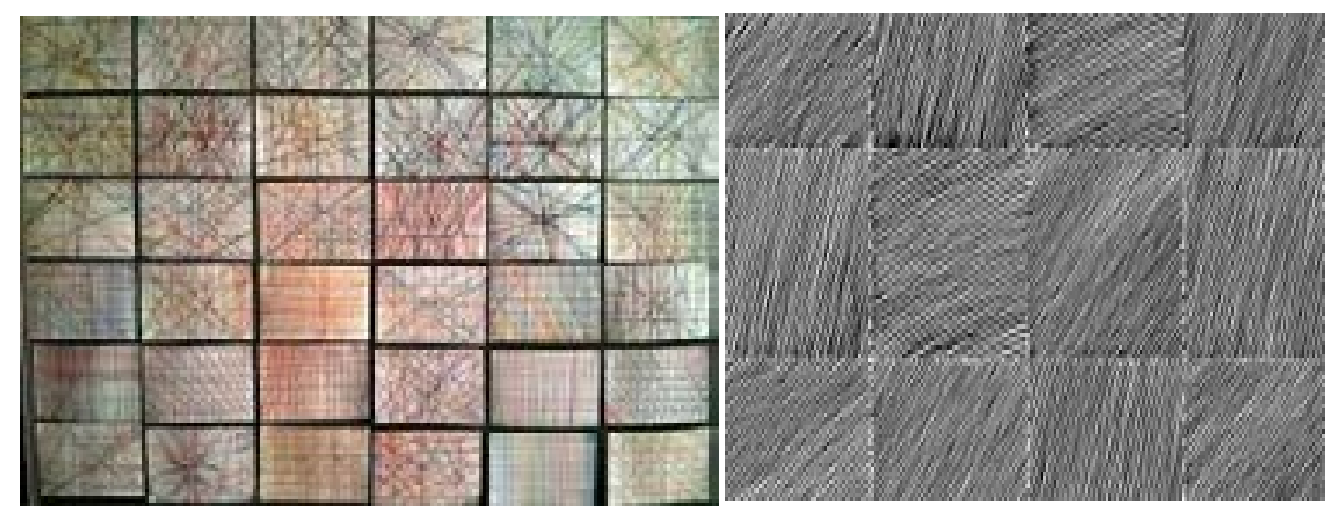

Fig-36-37 Joaquin Chancho, 2013 


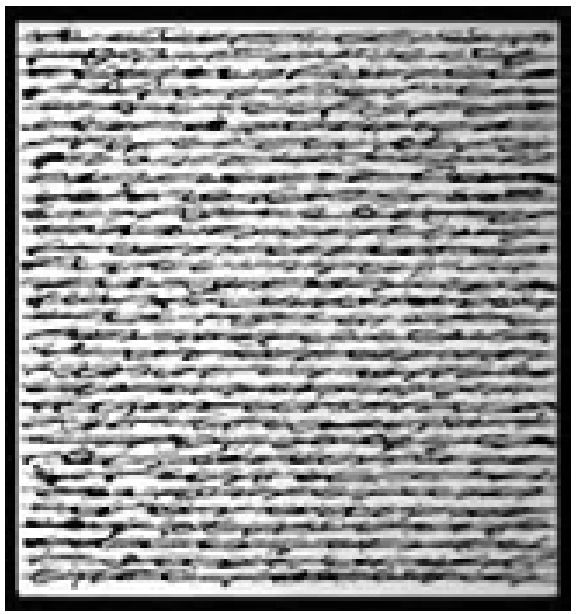

Fig-38 Joaquin Chancho, 2010

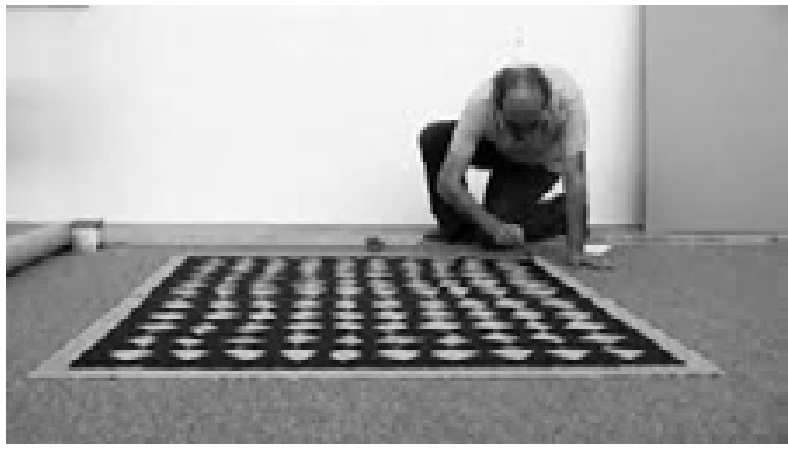

Fig-39 Joaquin Chancho 2010

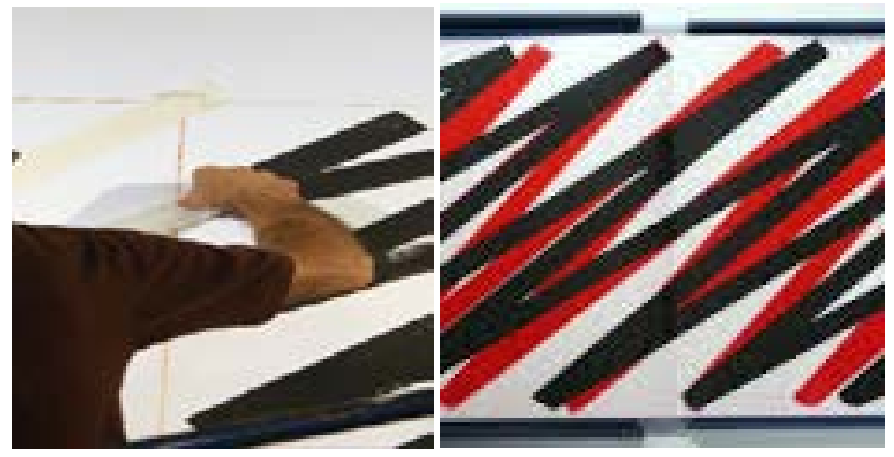

Fig-40.Joaquin Chancho 2010
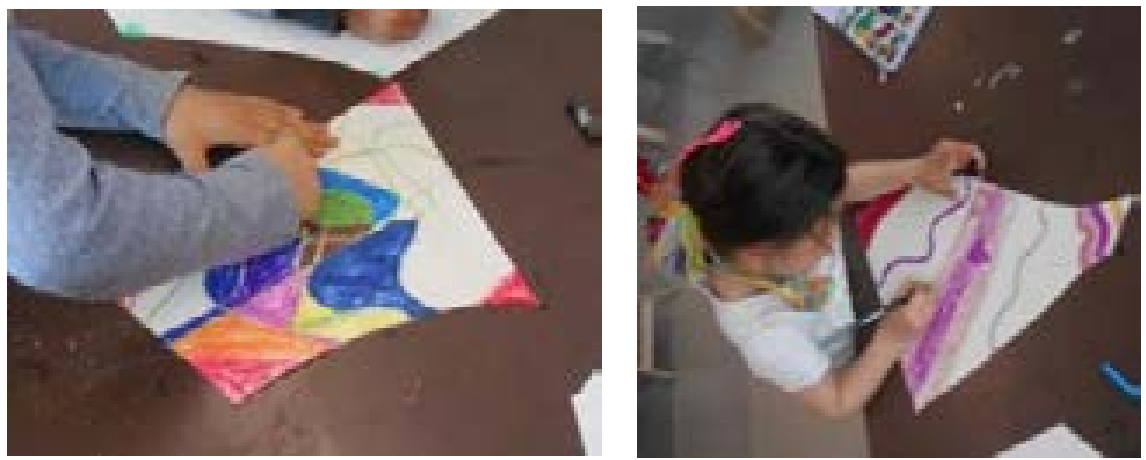

Figs- 41-42. Alumnos experimentando con distintos materiales 

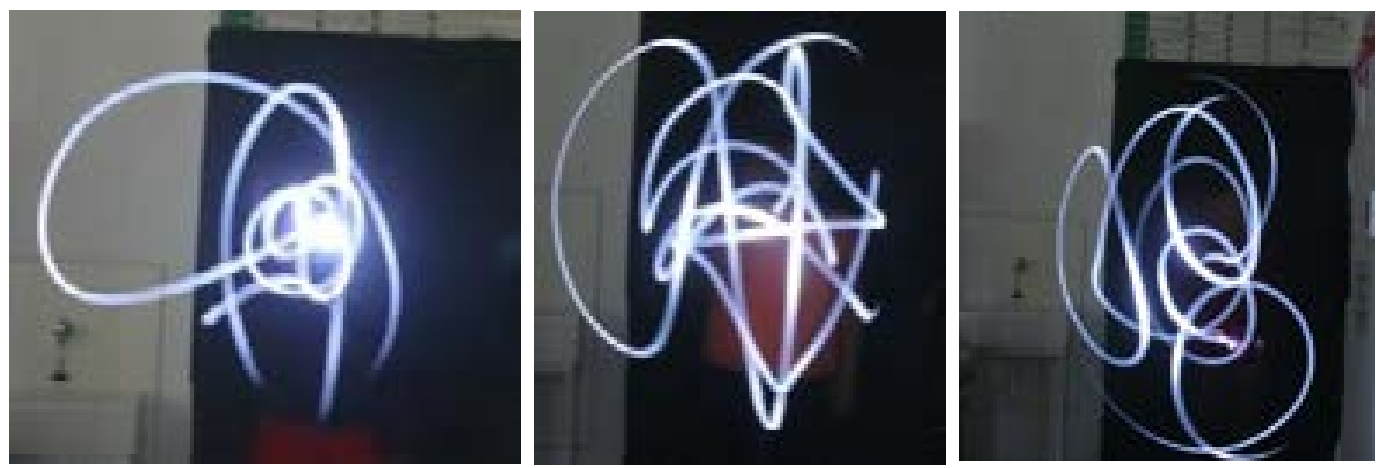

Figs.43-44-45-: Primeros garabatos experimentados por los alumnos.

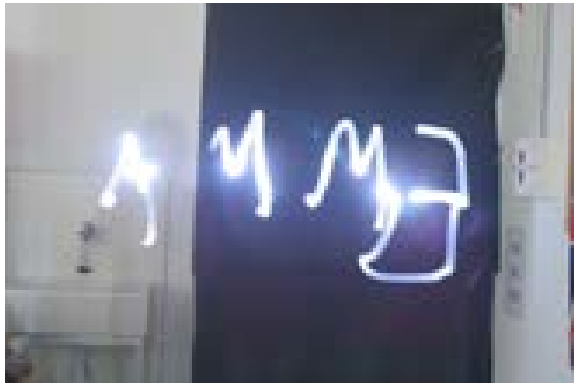

Fig-46. Intentando escribir su nombre (de derecha a izquierda)

\subsection{Resultados de la fase de creación artística}

En este último apartado del primer vértice de la triangulación, se evalúan las propuestas originadas por los propios alumnos a partir del bagaje obtenido en las dos primera fases del proyecto a fin de conseguir el último objetivo de investigación:

- Diseñar materiales didácticos sobre grafismo bajo las directrices emprendedoras.

En este caso, los criterios de investigación que permiten efectuar esta avaluación son el 3.1 y el 3.2, directamente relacionadas con habilidades de orden superior.

Durante la fase de creación artística los alumnos podían utilizar cualquiera de les variables aplicadas anteriormente, así como cualquier otra que apareciera de nuevo.

Dentro de esta dinámica surgía la posibilidad de que se produjeran interrelaciones entre variables.

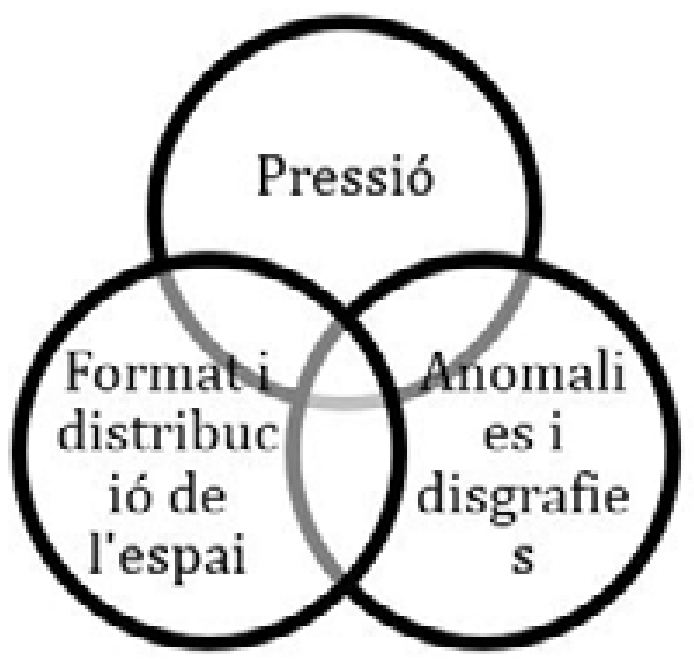

Fig-47.Fuente: Elaboración de los autores 

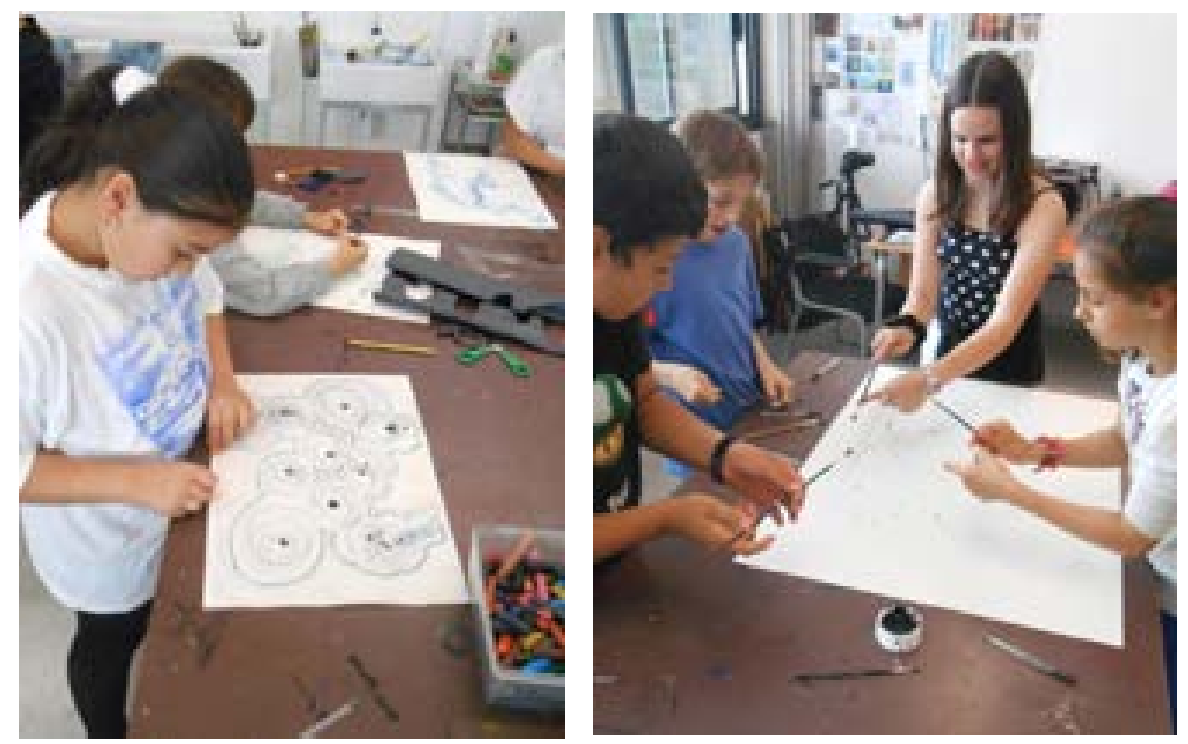

Fig. 47-48.. Imágenes de alumnos realizando diseños con la tabla gráfica y el ordenador para conseguir elaborar el Stop motion
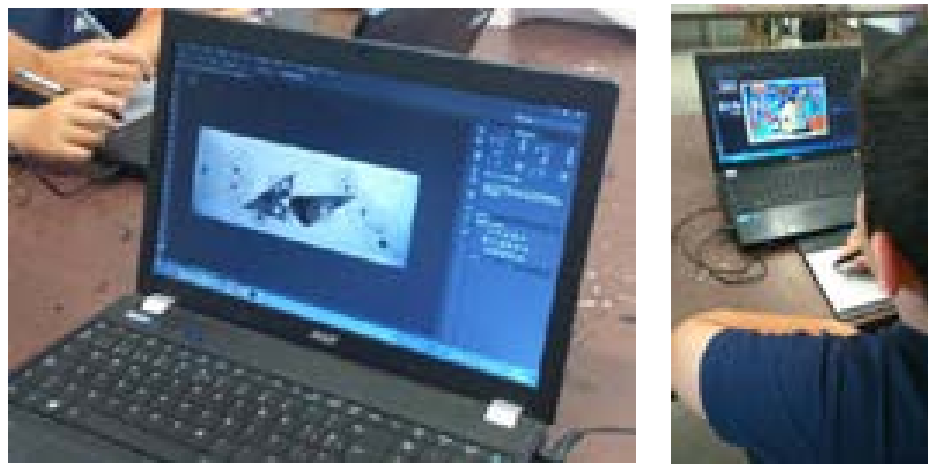

Fig-49-50. .Imágenes de alumnos editan Photoshop

Ante la imposibilidad de explicar todas y cada una de las actividades hacemos un breve resumen en el que se quiere destacar que la dimensión metacognitiva estaba presente en todas elles y que exige poner en marcha el pensamiento de orden superior especialmente escogido para el proyecto.

Transformamos por tanto la idea de hablar de creatividad y compromiso de trabajo en equipo todas aquellas cualidades básicas para afrontar el proyecto emprendedor. Por tanto, los resultados se valoran como positivos en el sentido que van orientados hacía el cambio de otra manera de hacer, enfocando a una gestión distinta tanto en el plano individual como de grupo.

\subsection{Segundo vértice: el marco teórico de la investigación}

En el marco teórico encontramos los principales ejes que sustentan la investigación. En el primero de ellos, se exponen algunos de los principios del PEC, como el valor que el equipo docente otorga a nuevos métodos de trabajo, así la efectuación de un breve proyecto donde la última fase se ha de llevar a cabo bajo un contexto emprendedor ha sido bien recibido. En la misma línea, tal y como manifestábamos en el segundo eje, el emprendimiento implica creatividad y compromiso, rasgos que el proyecto ha pretendido despertar en el alumnado. Las actividades de la fase de 
expresión ofrecen un amplio abanico de materiales y formatos diferentes, puesto que sólo con el bagaje significativo podrían activar la tercera fase de la investigación, donde se requería mayor poder de decisión por parte del alumnado. Masgrau, Forasté y Cros (2012) exponían en una de sus publicaciones sobre educación emprendedora que: "creatividad es sinónimo de flexibilidad, adaptabilidad, capacidad de improvisación o poder de decisión" (MASGRAU, FORASTÉ Y CROS, 2012, p.12).

Otro rasgo a destacar, mencionado en el primer eje, hace referencia a las dinámicas de trabajo, las cuales han sido variadas, des de tareas individuales hasta cooperativas y grupales; si bien, siempre bajo la guía y supervisión de los investigadores participantes. De esta forma, se han mantenido las dinámicas de grupo habituales del centro, dado que en la diversidad se encuentra la riqueza.

Las propuestas han pretendido desarrollar la competencia de autonomía y iniciativa personal, por medio de la zona de desarrollo próximo de Vigotsky (1931) de Castorina y Dubrovsjy (2004), aumentando progresivamente el grado de autonomía de la primera a la tercera fase (mayor exigencia cognitiva).

\subsection{Tercer vértice: opinión del grupo de investigación}

Dentro de la propia triangulación, emerge otra interior, originada por las opiniones de los miembros del grupo de investigación. Las encuestas, las fotografías, las grabaciones en video y otras evidencias, forman parte y quedan filtradas dentro de los argumentos de la discusión de este grupo de investigación.

Primeramente, según el primer objetivo de investigación, la primera de las fases del proyecto especialmente ha dado respuesta a la necesidad de una previa percepción de la propia grafía. Entonces, con estos conocimientos previos sobre sus letras y las de sus compañeros, los alumnos han podido dar paso con éxito a las actividades en el aula taller y en los demás contextos.

Respecto al segundo y tercer objetivo, la investigación ha debido ceñirse al tiempo del cual disponía, a la vez que centrarse en unas variables sobre grafismo que casaban más con el proyecto de escuela y con el alumnado de la muestra, dado que las circunstancias no permitían realizar prácticas de cualidad sobre más de tres variables. Es necesario destacar que hay un proceso madurativo que padecen los alumnos que debe acompañarse de la mejor manera posible, entonces, gracias a las prácticas propuestas ha habido una toma de consciencia de la faena en relación a esta temática.

Y, en lo que respecta al cuarto objetivo de investigación, como se exigía mucha dedicación y tiempo por parte del alumnado, no se ha podido lograr al cien por cien, aunque se puede estar satisfecho de los resultados obtenidos.

Se evidencia pero que, en su continuidad haría falta incidir principalmente en la última fase de creación artística, incidiendo en cómo hacer ver a los alumnos la diferencia entre un material cualquiera generado plásticamente y un material con contenido didáctico. Esta última sería una conclusión que daría pie a otra investigación en la que, este objetivo, se convertiría en uno de los principales.

Por otro lado, el investigador y autor del proyecto considera relevante destacar 
también que:

En cuanto al primer objetivo, el fomento de la autoestima se llevó a cabo principalmente mediante el feedback que se generaba en la primera fase del proyecto, especialmente, en el espacio individual transcurrido durante cada una de las encuestas. Se trataba de una fase de extracción de información, al mismo tiempo que de destacar los puntos fuertes de la grafía de cada alumno, teniendo en cuenta, que algunos todavía se encuentran finalizando el proceso de adquisición de esta.

En relación con el segundo y tercer objetivo, el primero de estos se ha logrado a través de la exhaustiva investigación teórica en la temática sometida a estudio; mientras que el otro ha sido gracias a las experiencias efectuadas en la fase de expresión del proyecto, tal y como se ha expuesto en el primer vértice de la triangulación.

$\mathrm{Y}$, respecto al último de los objetivos, ha de ponerse de manifiesto que se ha llegado a medio camino, tal y como se expuso en el punto 8.1.3. Los alumnos han estado capaces de idear actividades variadas, trabajando algunas de las variables implicadas en el grafismo y, además, generar ciertos materiales plásticos. Sin embargo, la categorización de estos materiales no puede ser definida como didáctica, a pesar de la buena disposición del alumnado en las producciones cometidas.

Para finalizar, y dejando de lado los objetivos, no puede olvidarse que es necesario incidir en esta cuestión a lo largo de toda la etapa de primaria, pero poniendo especial énfasis durante el ciclo inicial, que es donde termina la adquisición de la escritura, uno de los pilares básicos del grafismo.

\subsection{Valoración de las hipótesis y las preguntas de investigación}

Para cerrar este ciclo de análisis de los resultados, se hace imprescindible verificar o refutar las hipótesis iniciales de la investigación. A grandes rasgos, se puede exponer que la primera hipótesis ha sido verificada, mientras la segunda hipótesis tan solo lo ha sido parcialmente. Como se ha dejado constancia en otros apartados, la fluidez emprendedora se adquiere gradualmente, a lo largo del tiempo o, incluso, durante toda la vida. Entonces, la segunda hipótesis, coincidiendo con la segunda pregunta de investigación que resultaba el eje vertebrador del estudio, recalcaba que "¿Si se abriese una vía generadora de iniciativas emprendedoras que permitiese a los alumnos diseñar y elaborar materiales didácticos sobre problemas de grafismo comunes y detectados en lo experimentado con anterioridad?"; la respuesta es negativa según las circunstancias en que ha sido desarrollada la investigación. Si bien, es de suma relevancia un previo bagaje experimental que permita activar las actitudes y habilidades básicas del espíritu emprendedor como el dado a lo largo del proyecto.

\section{Conclusiones}

Si bien la práctica del grafismo aparece como un quehacer cotidiano de nuestra vida, no resulta tan sencillo realizar una definición adecuada de este tema, o sencillamente explicar a los niños a grandes rasgos a qué llamamos acto gráfico. Esta es la causa por la que los hemos introducido en este mundo a través de la experimentación y la manipulación de materiales didácticos que lo fomentan. 
Seguidamente, se llega a las conclusiones partiendo de los principales ejes que sustentan la investigación:

- Según los objetivos son los siguientes: las actividades ideadas deseaban poder sembrar nuevas maneras de trabajar el grafismo, otorgando la suficiente autoestima a los niños antes, durante y después de sus creaciones. No hemos querido cortar las alas de la creatividad, siendo solamente guías que les permitieran explorar y manipular todas sus producciones (tanto en la vertiente lingüística como en la artística) $y$, ciertamente, los resultados han sido muy variados y no muy precisos en relación a las diferentes variables estudiadas, aun habiendo podido visualizar los primeros brotes, para llegar a esta finalidad. El hecho de no poder continuar el desarrollo de cada alumno, si bien hemos podido constatar la evolución de su grafismo a lo largo de estos meses, no nos autoriza a afirmar con exactitud que todos los niños hayan adquirido la plataforma que les conducirá a adquirir esta habilidad ligada a la competencia de autonomía e iniciativa personal.

- Según las preguntas de investigación: sin duda el primer mes se llevó a cabo una observación sistemática óptima al centro y paralelamente una investigación teórica fuera de este contexto. Ambos actos generaron que la intervención educativa se centrara sólo en algunas variables del grafismo, a la vez que respondiendo a las particularidades de la muestra. Por otro lado, en relación a la creación de materiales didácticos, hemos de dejar constancia que no los podemos catalogar como tales. Si bien las propuestas responden a pilares emprendedores como la creatividad, el compromiso y las diversas dinámicas grupales $\mathrm{y}$, a pesar que han sido origen de un previo bagaje experimental, no responden fielmente a rasgos didácticos, producto de la edad de la muestra y del breve periodo temporal del cual se disponía.

- Según las hipótesis de la investigación: efectivamente, si otorgamos un amplio abanico de posibles prácticas, donde en cada una de ellas se incide en una variable determinada y se les hace reflexionar sobre esta en él durante y en el después de la experimentación, los alumnos acaban reteniendo rasgos característicos de esta variable en cualquier acto gráfico que realicen con posterioridad, tanto en la escritura como en la parte artística.

Por otro lado, al sacar provecho de estas reflexiones y habiendo resuelto las dificultades surgidas, se puede conseguir en mayor o menor grado un clima de trabajo emprendedor, siendo conscientes que los resultados pueden variar cualitativamente, puesto que cada niño presenta una realidad diferente.

\section{Bibliografia}

ALEMANY, L., MARINA, J. A., PÉREZ, J. M., PELliCER, C., ÁlVAREZ, B., I TORREJÓN, J. L. Aprendre d'emprendre: com educar el talent emprenedor (1a ed.). Barcelona: Planeta, 2013.

ARAGÜETE, P. R., LÓPEZ, S., I VILLAGRASA, M. R. La escritura: cómo conseguir un buen grafismo: prevención y atención de sus dificultades en el aula (1a ed.). Barcelona: Graó, 2015. 
ARANEDA, A. La triangulación como técnica de cientificidad en investigación cualitativa pedagógica y educacional. Revista de estudios y experiencias en educación, n. 5, p.11-38, 2006.

CASTORINA, J., I DUBROVSKY, S. Psicología, cultura y educación: perspectivas desde la obra de Vigotsky. 2004. Disponible en:

https://books.google.es/books?id=WAvo8T0GtXwC\&pg=PT25\&dq=vigotsky+zona+de+desarrollo+proximo\&hl=es\&sa =X\&ei=hKBnVYbHIYnpUtCJgKAB\&ved =0CCkQ6AEwAg\#v=onepage\&q=vigotsky\%20zona\%20de\%20desarrollo\%20proximo\&$\underline{f=f a l s e}$ Acceso en: 13 jun. 2016.

COLL, C., MARTÍN, E., MAURI, T., MIRAS, M., ONRUBIA, J., SOLÉ, I., I ZABALA, A. El constructivismo en el aula (1a ed.). Barcelona: Graó, 1993.

COSTA, J. La forma de las ideas: cómo piensa la mente: estrategias de la imaginación creativa. 2013. Disponible en: https://books.google.es/books?id=5zhFAgAAQBAJ\&pg =PT16\&dq =la +forma+de+las+ideas\&hl=es\&sa =X\&ei=k9xdVfSbK8OqU8mkgMAN\&ved=0CCAQ6AEwAA\#v=onepage\& $q=$ la $\% 20$ forma $\% 20$ de $\% 201$ as $\% 20$ ideas $\& f=$ false Acceso en: 13 jun. 2016.

ESCOLA PERICOT. Projecte Educatiu (extracte). 2013. Disponible en:

https://drive.google.com/file/d/OB9THJk4hUxkrejBIdXFmOG9Cbkk/edit?pli=1 Acceso en: 13 jun. 2016.

FERREIRO, E. Y TEBEROSKY, A. Los sistemas de escritura en el desarrollo del niño. (1a ed.). México: Siglo XXI, 1979.

GRAJALES, T. Tipos de investigación. 2000. Disponible en: http://tgrajales.net/investipos.pdf Acceso en: 13 jun. 2016.

JÁUREGUI, A. La creatividad como característica de los emprendedores. 2001. Disponible en: http://www.gestiopolis.com/creatividad-caracteristica-emprendedores/ Acceso en: 13 jun. 2016.

LAPIERRE, A., I AUCOUTURIER, B. Simbología del movimiento (1a ed.). Barcelona: Científico Médica, 1967.

LÓPEZ, J. C. La taxonomía de Bloom y sus actualizaciones. 2014. Disponible en: http:// www.eduteka.org/TaxonomiaBloomCuadro.php3 Acceso en: 13 jun. 2016.

LUÇART, L. Pintar, dibujar, escribir, pensar: el grafismo en el preescolar (1a ed.). Madrid: Cincel, 1980.

MASGRAU, M., FORASTÉ, A., I CROS, S. La educación emprendedora: un reto plural: De las ideas a los proyectos. La creatividad como pilar básico del emprendimiento. 
Aula de Innovación Educativa, n.213-214, p.10-15, 2012.

MASGRAU, M., I FORASTÉ, A. La educación emprendedora: un reto plural: sobre educación y emprendimiento. Aula de Innovación Educativa, v.213-214, p.57-62, 2012. MASGRAU, M. La poesia visual de J.M.Calleja. Vocació de gènere. Quadern de les idees, les arts i les lletres, n.192, novembre 2013.

RIGAL, R. Educación motriz y educación psicomotriz en Preescolar y Primaria. (1a ed.). Barcelona: INDE, 2006. 